US Army Corps

of Engineers ${ }_{\circledast}$

Engineer Research and

Development Center

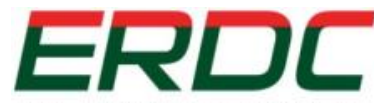

INNOVATIVE SOLUTIONS

for a safer, better world

\title{
Multivariate Bioclimatic Ecosystem Change Approaches
}

Robert C. Lozar and James D. Westervelt

February 2015

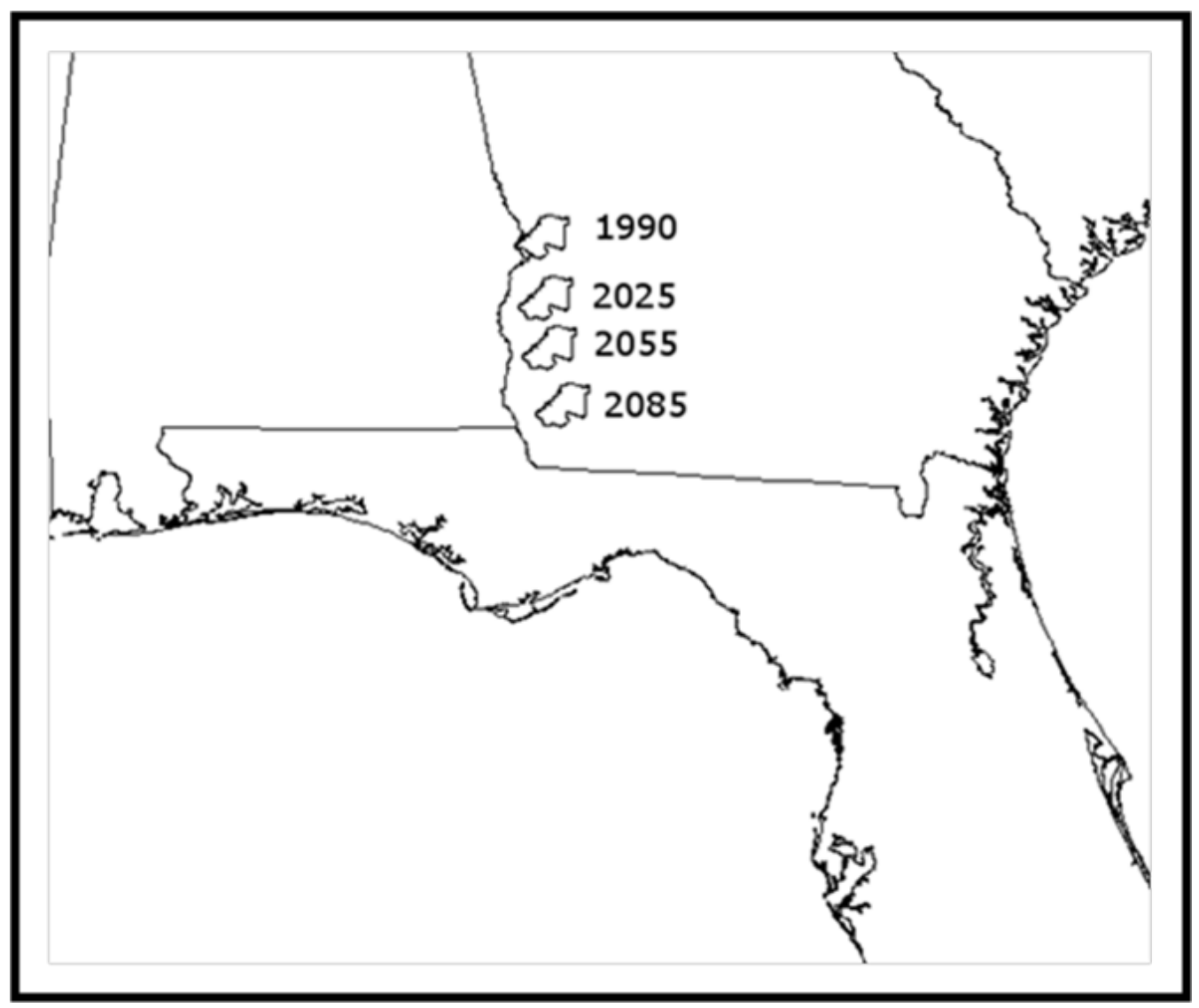


The US Army Engineer Research and Development Center (ERDC) solves the nation's toughest engineering and environmental challenges. ERDC develops innovative solutions in civil and military engineering, geospatial sciences, water resources, and environmental sciences for the Army, the Department of Defense, civilian agencies, and our nation's public good. Find out more at www.erdc.usace.army.mil.

To search for other technical reports published by ERDC, visit the ERDC online library at http://acwc.sdp.sirsi.net/client/default. 


\section{Multivariate Bioclimatic Ecosystem Change Approaches}

Robert C. Lozar and James D. Westervelt

Construction Engineering Research Laboratory (CERL)

US Army Engineer Research and Development Center

2902 Newmark Dr.

Champaign, IL 61822-1076

Final Report

Approved for public release; distribution is unlimited.

Prepared for Headquarters, US Army Corps of Engineers

Washington, DC 20314-1000 


\section{Abstract}

Changes in climatic parameters are important in that they affect the military's ability to perform its national defense mission and to manage military lands. The military must have the ability to predict climatic changes on specific installations. To support this need, the research tested and evaluated the application of six multivariate approach techniques to predict climatic changes on a specific Army installation, Fort Benning, GA. The six approaches were tested for their ability to identify where anticipated future conditions might be found today using a set of 19 bioclimatic parameters derived from climate change data. The evaluation found that the Primarily Analogous Multivariate approach developed during this research clearly distinguished itself from the other five approaches in that it successfully determined future climatic factors at the installation, as well as at the sub-installation level using the currently available climatic data.

DISCLAIMER: The contents of this report are not to be used for advertising, publication, or promotional purposes. Citation of trade names does not constitute an official endorsement or approval of the use of such commercial products. All product names and trademarks cited are the property of their respective owners. The findings of this report are not to be construed as an official Department of the Army position unless so designated by other authorized documents. 


\section{Contents}
Abstract ii

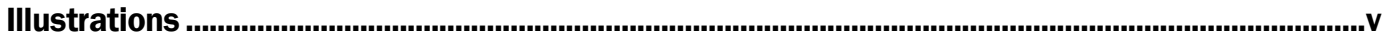
Preface ............................................................................................................................................................

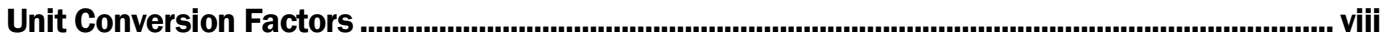
1 Introduction ................................................................................................................................. 1

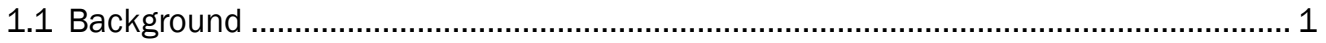

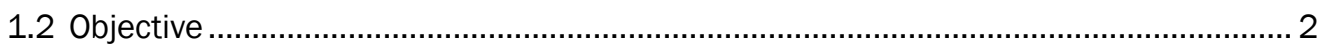

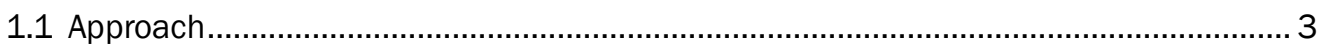

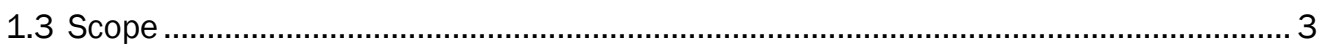
1.4 Mode of technology transfer............................................................................... 3

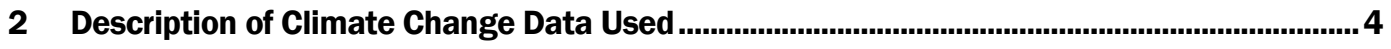

2.1 General concerns in the choice of the dataset adopted.............................................. 4

2.2 The Intergovernmental Panel on Climate Change ........................................................ 4

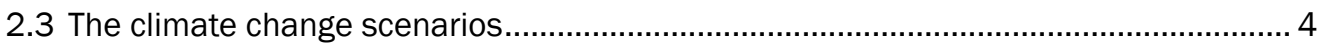

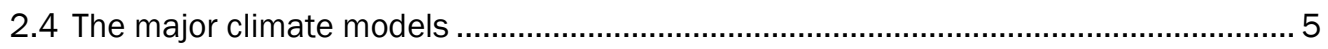

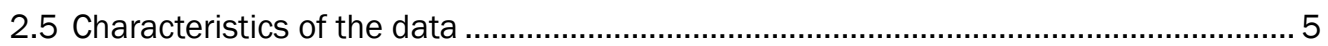

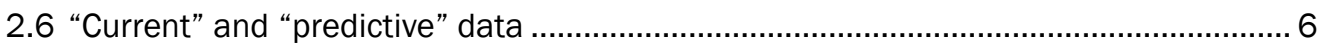

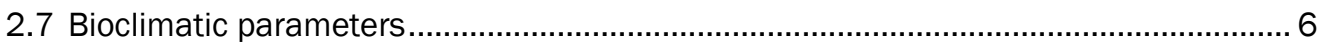

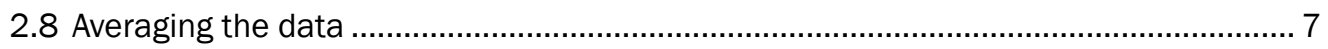

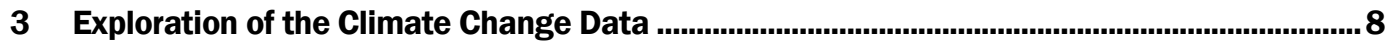

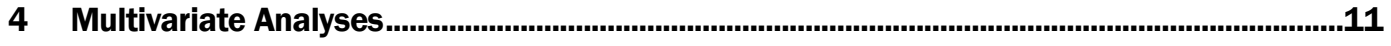

4.1 Background for multivariate analyses ............................................................ 11

4.2 Transforming the bioclimatic indices for MVA analysis .............................................. 13

4.3 Applying Unsupervised Classification ................................................................... 15

4.3.1 Effects of variable layer inputs on unsupervised classifications and class

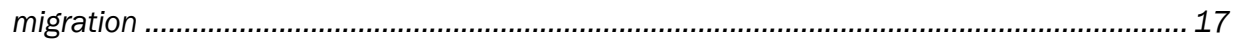

4.3.2 Ecosystem migration to Fort Benning............................................................................ 18

4.4 The Supervised Classification approach ............................................................... 23

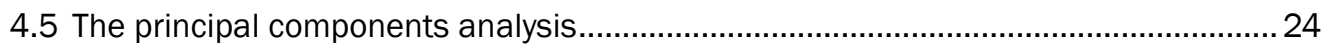

4.6 The Principally Analogous Multivariate (PAM) approach...........................................29

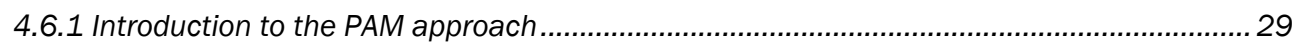

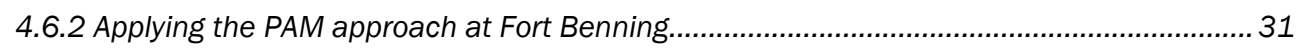

4.6.3 Migration of Fort Benning forest types - lowlands ........................................................... 34

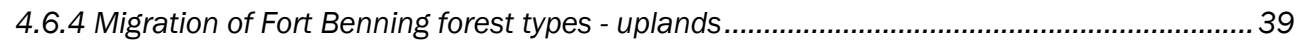

4.6.5 Analysis of the confusion between upland and lowland plant locations............................. 43

4.6.6 Invasive species based on the Primarily Analogous Multivariate approach....................... 45 


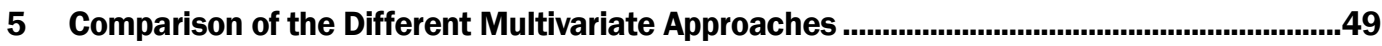

5.1 The evaluation of the different techniques............................................................. 49

5.2 The effect of the Benning Hole on the results ...........................................................50

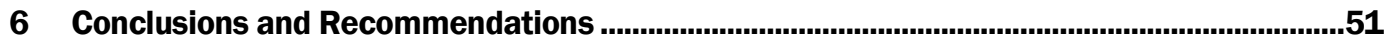

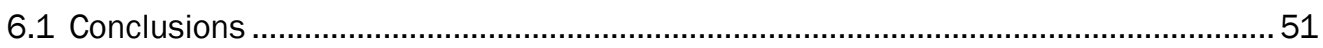

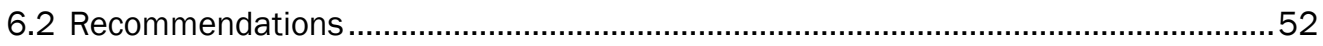

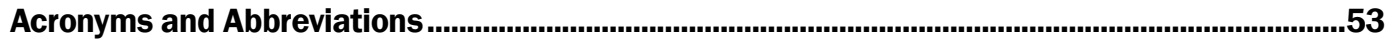

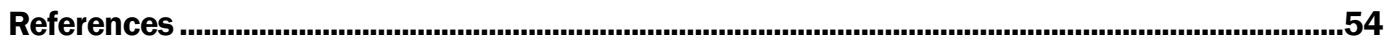

Report Documentation Page (SF 298) ..................................................................................57 


\section{Illustrations}

\section{Tables}

1 Bioclimatic categories used for climate change evaluations ................................................

2 Appearance of the Benning bull's eye in the bioclimatic layers...............................................

3 Cluster migration amounts 1990-2025 ……...................................................................17

4 Fort Benning climate character based on changed ecosystems..........................................22

5 Bioclimatic characteristics used in the Supervised Classification analysis ........................23

6 Characteristics of the PAM derived regions for each of the time periods for each

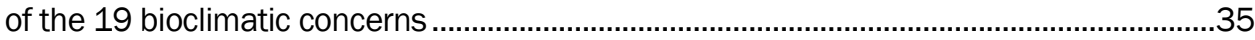

$7 \quad$ Upland vs. lowland confusion table in each of the time horizons .....................................45

8 Proposed exotic pest plant species for Georgia ....................................................................48

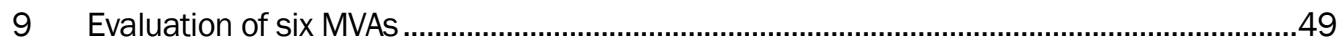

\section{Figures}

1 Bio12 annual precipitation exhibits the Benning "climatic hole". The darker blue represents locally lower precipitation. The image is in units of standard deviations from the dataset mean (explained later). The color table has been stretched greatly to enhance the "hole." Xs identify the locations of permanent weather stations

2 Multiple sample "bull's eyes" visible in the Annual Precipitation data. Units are in standard deviations from the image mean. Deep blue is the lowest precipitation, white is near the mean, and deeper reds are the highest values. Circles show obvious holes. Different color tables enhance different anomalies. Not all holes coordinate with weather stations

3 The clustering algorithm builds pixel clusters (right) based on the spectral reflectance's of the pixels.

$4 \quad$ Four layer clustering results for Fort Benning for 1990-2025 ….....................................19

5 Six layer clustering results for Fort Benning for 1990-2025 ..............................................19

6 Eight layer clustering results for Fort Benning for 1990-2025 ...........................................20

7 Migration of ecosystems into the Fort Benning region based on the Unsupervised Classification results for 2025

8 Supervised classification Category 16 that represents Fort Benning in the 2085 period (upper left), the 2055 period (upper right), the 2025 period (lower left), and the 1990 period (lower right).

9 First four components of the eight generated by the PCA for 1990. Axis 1 is upper left, Axis 2 is upper right, Axix 3 is lower left, Axis 4 is lower right

10 PCA resultant classes that occurred within Fort Benning in the 1990 time horizon (the darker the grey, the more commonly it occurred on the installation)

11 PCA resultant classes that occurred within Fort Benning in the 2025 time horizon 
12 The 19-dimensional bioclimatic PAM analysis for the Fort Benning study area. These analyses represent the migration of the climate away from the installation. The darker the area, the more analogous that location is to Fort Benning. The time horizons are: $a=1990, b=2025, c=2055$, and $d=2085$.

13 Locations from "where the future bioclimatic character of Fort Benning come." The time horizons are: $a=1990, b=2025, c=2055$, and $d=2085$

14 Upland landscape near the entrance to the Eufaula National Wildlife Refuge

15 Generalize species from the Fort Benning Forest Inventory map. Wetland types are in blue. The target areas are the blue within the circle centered on the Lower Upatoi Creek.

16 The 1990 bioclimatic distribution of cells that coordinate closely with the lowland tree species similar to the Lower Upatoi Creek from Fig. 25

17 PAM analysis for the distribution of lowland tree vegetation change in 2025. Right: The darker grey areas show all of distribution previously chosen for all of the installation (as shown in Fig. 13, upper right) while the lighter grey areas show just the lowlands chosen in this analysis. (All further graphics in this section will use this convention.) Left: Same analysis with geomorphology integrated into the result

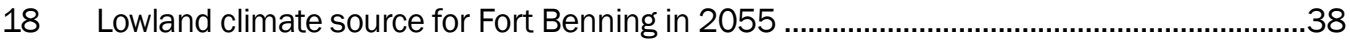

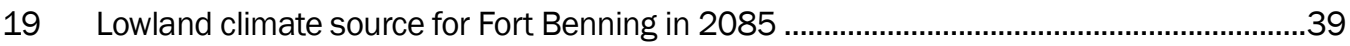

20 Alternative lowland climate source from Alabama for Fort Benning in 2085 .....................40

21 Generalize species from the Fort Benning Forest Inventory map. Upland types are in yellow. The target areas are the yellow within the circle centered on the southeast corner of the installation.

22 The 1990 bioclimatic distribution of cells that coordinate closely with the upland tree species similar to those in the southeast corner of Fig. 31............................................41

23 Fort Benning source for upland pine distribution for 2025 ...............................................42

24 Fort Benning source for upland pine distribution for 2055 .................................................42

25 Upland pine distribution for 2055 (from Fig. 24) draped over the topography map...........43

26 Fort Benning source for upland pine distribution for 2085 .................................................44

27 The distribution for the year 2025 of upland species (colored blue), lowland species (green) and where both upland and lowland species were identified in the same cell location (red).

28 The resultant PAM bioclimatic regions elsewhere in the world that are most similar in 1990 to the region around Fort Benning (the darker, the more similar)

29 The PAM analysis for 2085 for the bioclimatic regions that are most similar to the region around Fort Benning. 


\section{Preface}

This study was conducted for the Engineering Research and Development Center (ERDC) under the project, "Framework for Forecasting Climate Change Effects on Installation Natural Resources." The technical monitor was Alan Anderson, Technical Director, CEERD-CV-T. This project was part of the "Prediction and Adaptation of Military Natural Infrastructure in Response to Climate Change" work package under the direction of Dr. Timothy Hayden.

The work was performed by the Environmental Processes Branch (CN-N) of the Facilities Division (CF), Construction Engineering Research Laboratory (CERL). The CERL Principal Investigator was Dr. J ames Westervelt. William Meyer is Chief, CEERD-CN-N, and Michelle Hanson is Chief, CEERD-CN. The Deputy Director of ERDC-CERL was Dr. Kirankumar V. Topudurti and the Director was Dr. Ilker R. Adiguzel.

COL Kevin J . Wilson was the Commander of ERDC, and Dr. J effery P. Holland was the Director. 


\section{Unit Conversion Factors}

\begin{tabular}{|l|c|l|}
\hline Multiply & By & To Obtain \\
\hline acres & $4,046.873$ & square meters \\
\hline cubic feet & 0.02831685 & cubic meters \\
\hline cubic inches & 0.00001638706 & cubic meters \\
\hline degrees Fahrenheit & $(5 / 9) \times\left({ }^{\circ} \mathrm{F}-32\right)$ & degrees Celsius \\
\hline feet & 0.3048 & meters \\
\hline gallons (US liquid) & 0.003785412 & cubic meters \\
\hline inches & 0.0254 & meters \\
\hline miles (US statute) & 1.609347 & kilometers \\
\hline pounds (mass) & 0.4535924 & kilograms \\
\hline square feet & 0.09290304 & square meters \\
\hline square miles & $2,589,998$ & square meters \\
\hline tons (2,000 pounds, mass) & 907.1847 & kilograms \\
\hline yards & 0.9144 & meters \\
\hline
\end{tabular}




\section{Introduction}

\subsection{Background}

Climate model projections summarized in the 2007 Intergovernmental Panel on Climate Change (IPCC) report (IPCC 2007a) indicate that global surface temperature is likely to rise between 1.1 and $6.4{ }^{\circ} \mathrm{C}$ during the $21 \mathrm{st}$ century. In February 2010, in response to climate change forecasts, the President's Council on Environmental Quality (CEQ) issued draft guidance to all Federal agencies concerning the manner in which climate change should be included in the evaluation of environmental effects under the National Environmental Policy Act (Sutley 2010). Specifically, the guidance states that:

Agencies should consider the specific effects of the proposed action (including the proposed action's effect on the vulnerability of affected ecosystems)...

The Quadrennial Defense Review (QDR) was the first high-level Department of Defense (DoD) publication to address the issue of the growing need to consider risks and response strategies for climate change (DoD 2010). In the QDR the DoD explicitly acknowledged that climate change will likely affect the nature and scope of future missions, as well as training and testing assets of military installations.

Installation-level Integrated Natural Resources Management Plans (INRMPs) provide an appropriate context for considering such climate change impacts (Legacy 2009). Natural communities require decades to mature and evolve. At the installation level, the purpose of the INRMP is to plan, and to coordinate with other stakeholders in the region, landscape or ecosystem level management over long time periods. The goal of INRMP is to ensure both good stewardship and no net loss of the lands that support the military mission.

To ensure that the Army will meet its training and materials testing requirements in the future, it must be able to anticipate climate-induced changes that may affect the activities at each of its major installations. To do this, the most basic need is to identify how the environmental 
conditions that support the local ecosystems might shift, especially if that shift favors a different (i.e., changed) ecosystem. However, most literature examining the effects of climate change on military installations has dealt with the effect of rising sea levels on coastal areas, a concern more important to Navy and Marine interests than to Army installations. Installation land managers and planners need scientifically reliable information that addresses climate change in the context of the ecosystems in which they reside.

To meet this need, the Army formed a climate change working group to undertake a high-level climatic change assessment to better target military concerns. * The initiative is intended to assess vulnerabilities across locations and missions at a regional scale and to integrate climate change considerations into installation plans and assess technical assistance needs. Specifically, the effort will help land managers maintain installation lands if (and when) the ecosystem changes, while still supporting the installations' military mission. This study is one in a series (Lozar 2011, 2012a, 2012b; Westervelt 2011) that focuses on those needs at individual military installations. This work analyzes forecasted ecosystem shifts around Fort Benning, GA and attempts to predict the geographic locations of combinations of environmental conditions and the ecosystems associated with those conditions.

\subsection{Objective}

The overall objective of this project is to explore approaches that can help installation natural resource managers anticipate ecosystem stresses and shifts that may occur in response to continued climate change. The specific objective of this work was to identify geographical areas that currently experience environmental conditions that are the same as climate conditions forecasted to occur at target location in the future. A secondary, related objective was to determine whether currently available climatic data were sufficient to successfully analyze climate change at the sub-installation level with the currently available climatic data.

\footnotetext{
* http://www.army.mil/article/101844/Climate_Change_Task_Force/
} 


\subsection{Approach}

The objectives of this work were met in the following steps

1. Climatic data was obtained from various authoriative sources. These consisted of 19 bioclimatic parameters that represented Global Climatic Models (GCMs) and three future scenarios for each of the time periods centered around the dates 1990, 2025, 2055, and 2085. A consensus database was created from these sources. This database formed a solid foundation that made it possible to reliably track the predicted changes.

2. Four Multivariate Analysis (MVA) techniques were applied to climate change data pertaining to the area around Fort Benning, GA to determine the relative ease and efficacy of the different techniques.

3. The results from the application of the techniques were compared and evaluated.

4. Conclusions were drawn and recommendations made for future research.

\subsection{Scope}

This investigation inspects the data and analysis techniques already available. No attempt was made to generate new climate change preditions techniques or to program new software. This work used scientifically validated climate change data, not weather or weather extremes, and assumed that the military missions at installations will remain the same as they are today.

\subsection{Mode of technology transfer}

It is anticipated that the results of this work will be used to further development of techniques to predict future climatic factors on the installation and sub-installation level. 


\section{Description of Climate Change Data Used}

\subsection{General concerns in the choice of the dataset adopted}

Research scientists are particularly sensitive to the issue of choosing data biased toward a particular predisposition. Although military groups do have "favored" datasets for climatic change research, this research took great care to follow guidelines in choosing data that provided the greatest viability and overall acceptance. Those guidelines include using data that were:

- generated by others (outside the local research group) with specialized expertise

- generated in a documented, scientifically accepted manner

- freely available to ensure easily and accurately repeatable research.

These guidelines were adopted not only to ensure that the results of this work will be scientifically valid, but also to ensure that they will be compatible with any dataset eventually the military chooses to adopt.

\subsection{The Intergovernmental Panel on Climate Change}

The most respected GCMs generate predictions based on a set of conventions disseminated through the IPCC. Such standardization is meant to facilitate comparison between models. The IPCC reports (2007b) are intended to reflect the scientific consensus among the experts in the field. All data used in this research follow the IPCC standards.

\subsection{The climate change scenarios}

The IPCC has established a series of standard future scenarios to assist with coordination and comparison between modeling efforts. This international standard set of scenario types, named the "SRES" (after "The Special Report on Emissions Scenarios"), was prepared by the IPCC for the Third Assessment Report (TAR) in 2001 on future emission scenarios to be used for driving GCMs to develop climate change scenarios. The SRES were also used for the Fourth Assessment Report (AR4) in 2007. 
This work used these SRES emission scenarios:

- A1(B): globally homogenous rapid economic grouth

( with $\mathrm{B}$ variation $=\mathrm{a}$ balanced usage of both fossil and nonfossil fuel energy sources)

- A2: locally heterogeneous, regionally oriented economic growth

- B1: globally homogenous sustainable economic growth.

\subsection{The major climate models}

About 21 major GCMs were used in the development of AR4. This research chose to use the models that have had the greatest number of validation studies and the longest period of development (1 to 2 decades):

1. GFDL Model - NOAA Princeton (gfdl_cm2_1)

2. NASA GISS (giss_model_er)

3. United Kingdom Hadley Model (ukmo_hadcm3)

4. Canadian (CCCma) Model (cocma_cgcm3_1_t47)

5. NCAR Boulder (ncar_cosm3_0)

6. Australian Model (csiro_mk3_5).

Note that the Fifth Assessment Report (the AR5) is in progress at the time of this writing. While the data are just becoming available, the types available are not nearly as mature as those based on the AR4 work (IPCC 2013). For this reason, the most recent model results (the AR4) were used in this study.

\subsection{Characteristics of the data}

The GCM data used here have been downscaled or refined from their initial resolution by integrating the data with more local concerns such as topography, surface winds, evaporation, and local precipitation (Archive Collaborators 2013). Downscaling using statistical approaches produces maps with patch resolution down to 30 arc-seconds ( $\sim 800$ meters) on an edge. Data at this resolution were used in the analyses described in this report.

The data used were averaged over a 30-year period. For simplicity, this report refers to the entire period using the midpoint date of the period. For example, the period of 2010 to 2039 will be referred to as "2025." 


\section{6 "Current" and "predictive" data}

The WorldClim dataset (Hijmans et al. 2005), which represents downscaled data from weather stations averaged over a period of 19502000, was used to represent "current" conditions (WorldClim 2013). This dataset contains global maps of the minimum, mean, and maximum temperatures and rainfall by month over the period of 1950-2000. It is based on interpolation of weather station data from across the globe that have been adjusted for the effects of elevation. This report uses the term "current" to refer to this dataset.

For the IPCC analyses the various GCMs are run using inputs defined by the various potential future emission scenarios. This work selected six representative models and three emission scenarios (introduced above), resulting in 18 different forecasts. The International Centre for Tropical Agriculture (CIAT) has downscaled these climate projections from the IPCC GCM model results (Ramirez and J arvis 2010). Their approach, called the delta method, compares the forecasted average monthly temperature and rainfall differences for each GCM grid cell (typically 2-3 degrees resolution) with the historic record and then applies that change to the WorldClim databases at 30 arc-seconds resolution. The result is a detailed forecast of the consequences of climate change at less than a $1-\mathrm{km}$ resolution over the earth's landmass.

\subsection{Bioclimatic parameters}

The basic WorldClim and CIAT maps provide average temperature and rainfall for each month over historic and future time periods. From this information, a set of secondary datasets are created to include 20 bioclimatic concerns useful in characterizing the biological environment based on the predicted GCM changes. These 20 parameters (Table 1) represent many of the concerns that affect the living environment in a locality. They are derived directly from the base temperature and precipitation data. Characteristics of the data are well documented at the CIAT web site. These are the data types used in the MVA. 
Table 1. Bioclimatic categories used for climate change evaluations.

\begin{tabular}{|c|}
\hline Derived from maximum and minimum temperature $\left({ }^{\circ} \mathrm{C} \times 10\right)$ : \\
\hline BI01 = Annual Mean Temperature \\
\hline $\mathrm{BIO} 2=$ Mean Diurnal Range (Mean of monthly $(\max$ temp - min temp $))$ \\
\hline $\mathrm{BIO3}=$ Isothermality (mean diurnal range/temperature annual range) \\
\hline BIO4 = Temperature Seasonality (standard deviation *100) \\
\hline BI05 = Max Temperature of Warmest Month \\
\hline BI06 = Min Temperature of Coldest Month \\
\hline BI07 = Temperature Annual Range (P5-P6) \\
\hline BI08 = Mean Temperature of Wettest Quarter \\
\hline $\mathrm{BI09}=$ Mean Temperature of Driest Quarter \\
\hline BI010 = Mean Temperature of Warmest Quarter \\
\hline BI011 = Mean Temperature of Coldest Quarter \\
\hline Derived from precipitation (in centimeters): \\
\hline BI012 = Annual Precipitation \\
\hline BI013 = Precipitation of Wettest Month \\
\hline BI014 = Precipitation of Driest Month \\
\hline BI015 = Precipitation Seasonality (Coefficient of Variation) \\
\hline BI016 = Precipitation of Wettest Quarter \\
\hline BI017 = Precipitation of Driest Quarter \\
\hline BI018 = Precipitation of Warmest Quarter \\
\hline BI019 = Precipitation of Coldest Quarter \\
\hline Additional dataset: \\
\hline $\begin{array}{l}\text { BIO20 = Consecutive Months }- \text { the maximum number of consecutive dry months of } \\
<100 \mathrm{~mm} \text { in a year }\end{array}$ \\
\hline
\end{tabular}

\subsection{Averaging the data}

Six different climate models and three different emission scenarios produce 18 sets of forecast results for three future time periods. This study averaged the forecasts for each of the time intervals. That is, the 18 results (from the six GCMs and three scenarios) were averaged together for each of the maps in Table 1 and for each of the future time periods. The results represent the scientific consensus of the best models available. It also eliminates the controversy that seems to always emerge when extreme values from one model are unfavorably compared to those of another. Finally it simplifies and clarifies the task of comparing the results of the MVA. 


\section{Exploration of the Climate Change Data}

The WorldClim and associated CIAT dataset is based on historic rainfall and temperature readings from weather stations around the world. Local equipment or settings for the weather station can result in readings that are uncoordinated with surrounding weather stations. The interpolation algorithms used to populate a field of readings between stations can result in slight errors that can be revealed as "holes," circular patterns, or "bulls eyes," depending on the color table used. The area near Fort Benning can be characterized as a region of rolling low hills. In such an area, one would expect that the climatic factors will smoothly vary as if a curtain were draped over the terrain. Locally, the smoothness of the curtain would be expected to moderate only because topography has subtlety been integrated into the bioclimatic data through the WorldClim downscaling process. For the area in close proximity to Fort Benning, the data show something dramatically different than expected.

Examination of the original maps revealed an interesting pattern. Almost centered on the installation is a local data anomaly (Figure 1). In this image, the highly enhanced color table proceeds from red, to dark red, to green, to dark green, to blue, and finally to dark blue as the precipitation increases.

The climatic pattern does not just correlate with topography, which can be seen subtlety matching stream patterns. The Benning bull's eye is evident in the maps of those bioclimatic factors listed in Table 2.

Table 2 lists eight concerns that clearly exhibit the bull's eye. Seven are associated with precipitation while only one is exclusively related to temperature. This means that precipitation is the overriding concern contributing to the climatic anomaly pattern in most of the secondary data layers. The image in Figure 3 suggests that Fort Benning is more intrinsically related to the precipitation amounts $65 \mathrm{~km}$ to the east of the installation than to areas immediately surrounding the Fort. Anyone studying Fort Benning in isolation or the immediately adjacent area would not detect this feature since its presence does not emerge until the study area is drawn out to roughly $15 \mathrm{~km}$ beyond the installation's eastern boundaries. 
Figure 1. Bio12 annual precipitation exhibits the Benning "climatic hole". The darker blue represents locally lower precipitation. The image is in units of standard deviations from the dataset mean (explained later). The color table has been stretched greatly to enhance the "hole." Xs identify the locations of permanent weather stations.

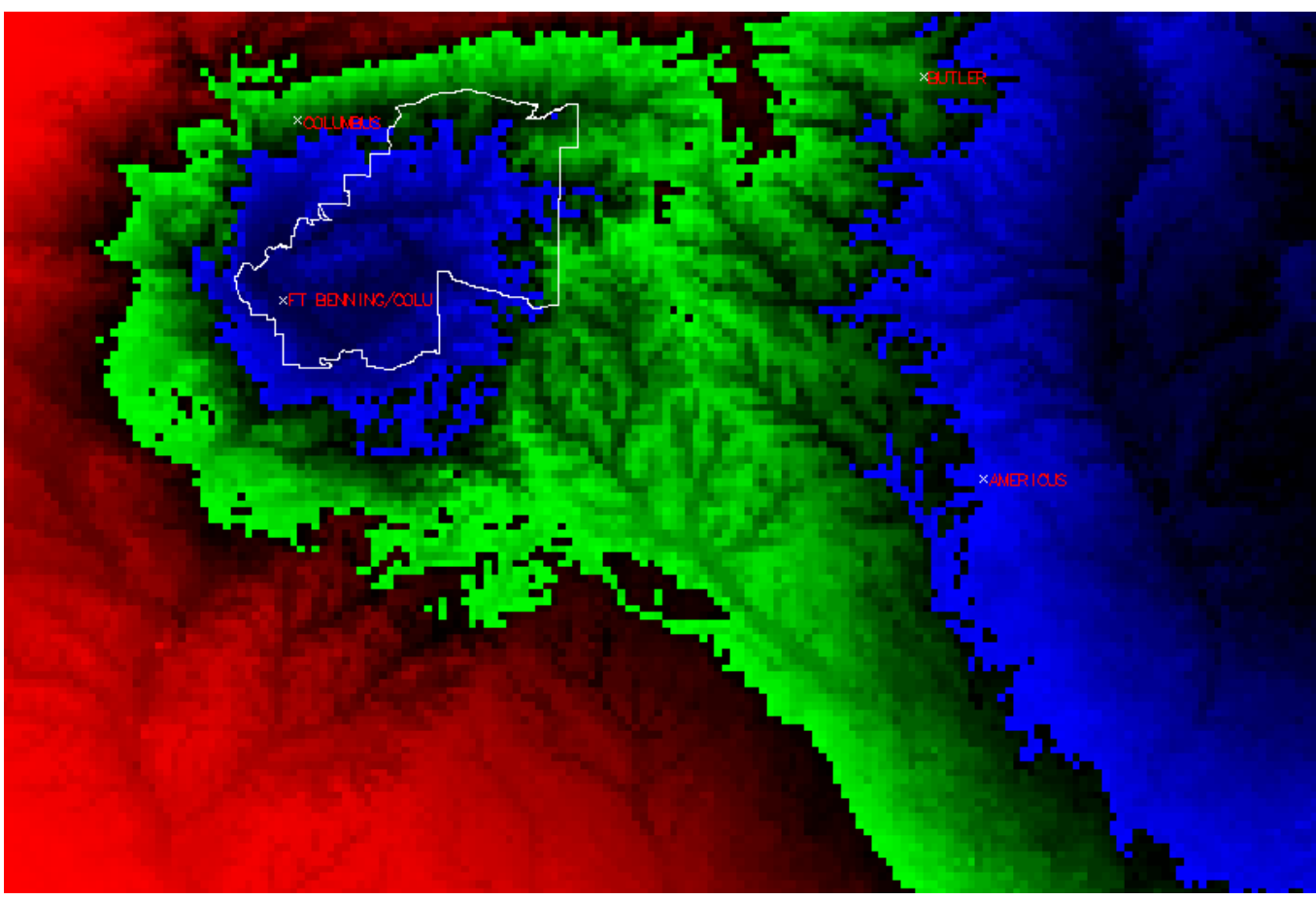

Table 2. Appearance of the Benning bull's eye in the bioclimatic layers.

\begin{tabular}{|c|l|c|c|}
\hline BioNumber & Meaning & $\begin{array}{c}\text { Associated with } \\
\text { Precipitation }\end{array}$ & $\begin{array}{c}\text { Associated with } \\
\text { Temperature }\end{array}$ \\
\hline Bio8 & Mean Temperature of Wettest Quarter & Yes & Yes \\
\hline Bio10 & Mean Temperature of Warmest Quarter & No & Yes \\
\hline Bio12 & Annual Precipitation & Yes & No \\
\hline Bio13 & Precipitation of Wettest Month & Yes & No \\
\hline Bio14 & Precipitation of Driest Month & Yes & No \\
\hline Bio16 & Precipitation of Wettest Quarter & Yes & No \\
\hline Bio17 & Precipitation of Driest Quarter & Yes & Yes \\
\hline Bio19 & Precipitation of Coldest Quarter & Yes & \\
\hline
\end{tabular}

The hole can be thought of as an anomaly in the smoothly draped curtain of data. In fact, it is a thumbprint depression, which in essence extends the precipitation character that exists to the east pulling it toward the location of Fort Benning. It is significant in that it sits over the target Army installation like a "bulls eye" mark. It suggests that an errant set of readings may originate from the southern quarter of the installation. In Figure 1, each weather station is labeled by name plotted with an "x." The weather stations are the source for the data that the WorldClim-based climate 
downscaling process uses. In fact, the Fort Benning weather station does reside in the hole, though not at its center. It must be suspected that readings from this station might be the source of the data hole.

Figure 2 displays the CIAT Bio12 annual precipitation map. Sixteen or more bull's eyes can be seen. Evidently, when the data was being generated, the smoothing algorithm spawned local holes and hills. Since it seems to be a common occurrence, it is apparently one of the drawbacks of using downscaled data.

The point of this discussion is that this bull's eye artifact has multiplied itself in some of the derived data layers. It is therefore predicted that the Benning Hole will appear in the results of the multivariate classifications. Also, it can be expected that patches $50 \mathrm{~km}$ to the east of the installation will be more similar to the installation than will areas either on the installation or more immediately adjacent to it. In fact, many of the resulting category identifications do have a very strong east-west bias. Specifically, it appears in both the Unsupervised and Supervised Classification results.

Figure 2. Multiple sample "bull's eyes" visible in the Annual Precipitation data. Units are in standard deviations from the image mean. Deep blue is the lowest precipitation, white is near the mean, and deeper reds are the highest values. Circles show obvious holes. Different color tables enhance different anomalies. Not all holes coordinate with weather stations.

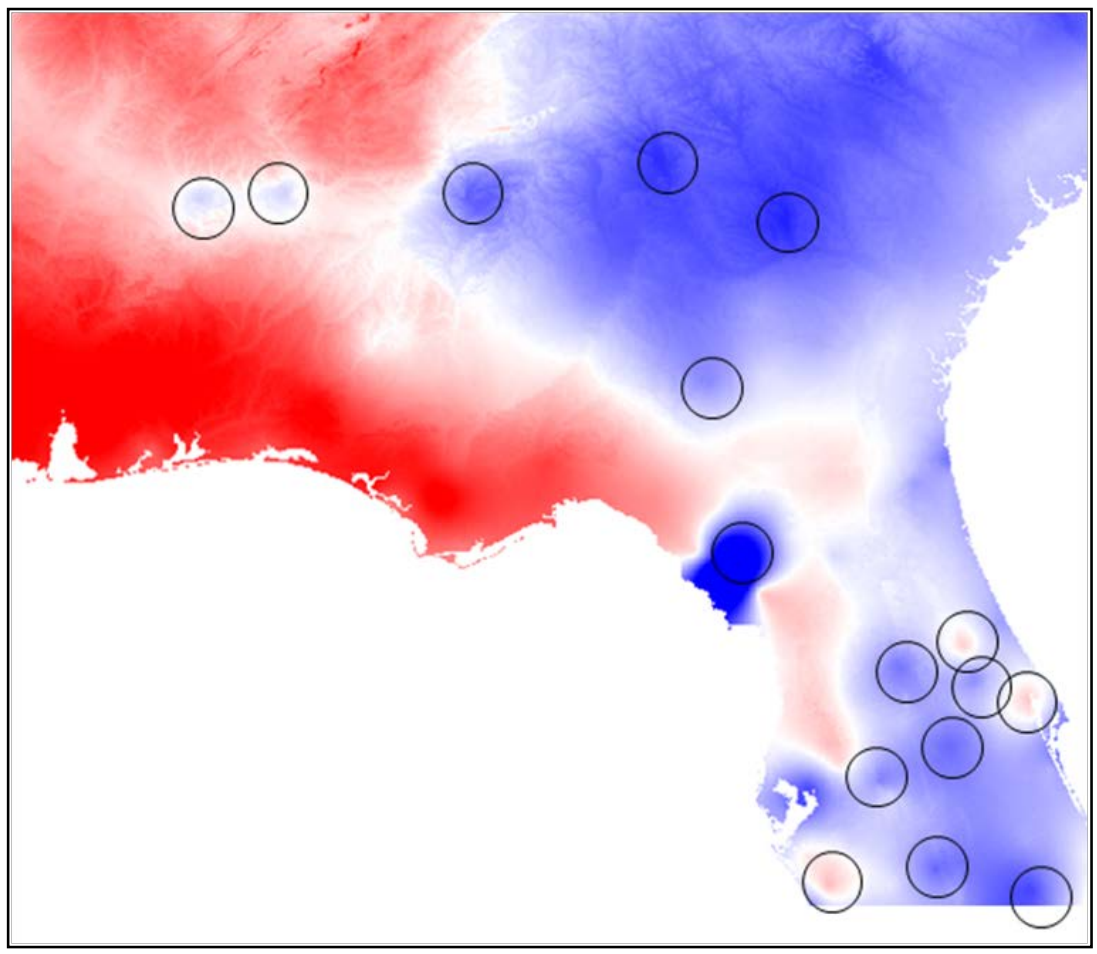




\section{Multivariate Analyses}

The goal of this work is to identify current locations that have the combination of climate characteristics that are anticipated for the installation, Fort Benning, in the future. One approach is to simply identify areas that have exactly the same set of characteristics. Unfortunately, there is no guarantee that a current location will have the identical combination of values anticipated in the future. By setting acceptable ranges of values for each of the variables, it is possible to begin to identify similar areas. The challenge that immediately arises is how to establish ranges that are equally valid. The same challenge exists in the processing of satellite (or high altitude) imagery to identify locations of similar land cover. Such imagery is typically associated with grey-scale images representing several to many different wavelengths that are statistically processed using MVA, which has been adopted to address the challenge of locating similar areas.

\subsection{Background for multivariate analyses}

An MVA is based on the statistical principle that involves observation and analysis of more than one statistical outcome variable at a time. In the area of land planning, MVAs have been traditionally applied to satellite images. In this area, the variables are normally seen as the three grey-scale images taken by a spectral sensor in the red, green, blue, and often infrared parts of the spectrum. However, multispectral satellites often sense five to about 15 distinct spectral bands. Newer satellite imaging systems generate many images each taken in a narrow band width in the radiation spectrum.

These newer satellite imaging systems are called hyper-spectral systems. Traditionally values from these bands have been submitted to a mathematical manipulation routine (an MVA program) to generate patches that represent distinct concerns, normally those concerns being distinct land cover types. Mathematicians have developed several distinct algorithms to analyze the input bands. These multivariate programs are now readily available for application in software packages. With the increase in the number of spectral bands available, programs have been written to handle a large number of bands at the same time. However these programs do not distinguish whether an input band is a visual "photographic" style satellite 
image or set of data, as long as there is an $\mathrm{X}$ and a $\mathrm{Y}$ component on a compatible Cartesian system and a value (also called a Z) at a particular point. The obvious example of a non-image dataset is that of topographic elevation where the z-values really do physically represent the third dimension of height. Thus, an elevation map can be considered another image, though it is by no means a spectral image.

It is easy to extend the concept to allow the submittal of red, green, blue imagery bands along with an elevation dataset to a multivariate classification program. The result of this analysis might therefore be land uses distinguished by elevation, as well as spectral reflection. Multivariate images arise from a surprising variety of sources: temperature, gravitational field, impedance, magnetic field, electrical field, mass, wavelength, ultrasound wavelength, polarization, electron energy, etc. Common subdivisions of the scientific imaging fields includes satellite imaging, medical (clinical) imaging and in microscopy. As long as an image has two pixel indices (e.g., an $\mathrm{X}$ and $\mathrm{Y}$ location in the image plane) and a variable quantity to make a three-dimensional array, it can be used as one of the components in an MVA analysis.

For the purposes of this work, it is desirable to substitute climatic indices for spectral bands for submission to MVA routines to determine how climate change will alter the environment around military installations and to predict what the new climatic conditions will be in the future. Fort Benning GA is the focus of the actual analyses here, though they can be applied to any other installation.

The application of MVA techniques using climate data has been demonstrated (Hargrove 2004, Westervelt 2011). In this work, four techniques were successfully applied: (1) Unsupervised Classification, (2) Supervised Classification, (3) Principal Components, and (4) the Primarily Analogous Multivariate approach. Canonical Components Analysis (CCA) and Sequential Maximum A Posteriori (SMAP) estimation were attempted, but no usable signature file could be generated. Others like Tassel Cap are specific to particular satellite sensors and were not appropriate for this application (ERDAS 2010). 


\subsection{Transforming the bioclimatic indices for MVA analysis}

The bioclimatic maps needed to be prepared for submission to the multivariate classifiers. The multivariate classifiers usually expect the data to have the following characteristics:

- They must range between 0 to 255 (inclusive).

- The histogram distribution should have a semi-normal distribution (i.e., tails that contain few values with values peaking at one value).

- The histogram distribution should be continuous .

Part of the problem with the bioclimatic data layers is that ranges can be negative (e.g., temperatures below $0{ }^{\circ} \mathrm{C}$ ); an index range can vary from -1 to +1 , and maximum values can range into the thousands. To make the different data layers compatible, it was necessary to normalize the data without losing the information value it contained.

One might think that an obvious and straightforward approach would simply involve scaling data values from their actual minima and maxima to a scale from 0 to 255 . Unfortunately this is not appropriate because it assumes that the ranges and increments are equally important. For example, if the range of the raw bioclimatic parameter of $X$ for 2025 was 25 to 100 and the range for the comparable 2055 data was 25 to 80 , when these layers were rescaled between 0 to 255, both would range from 0 to 255 , implying the maximum values were the same. However it is clear that the data for 2055 show an important change - a decrease in the maximum. This important change is lost in rescaling from 0 to 255. A means of normalizing all the data layers while preserving the character of the raw data is needed.

The technique adopted was to generate layers that showed how far each value was from the layer mean as measured in units of standard deviations. If the full data set is used to generate the resultant values, these values are called the " $z$ values." If a sampling of all the data is used to generate the resultant values, the values are call "students-t distribution." Both are common statistical techniques (Sprinthall 2003). The technique used is a cross between the two. More importantly, the results are all in the same units, standard deviations. 
The first step is to calculate the mean and standard deviation across the population for each layer. For each bioclimatic parameter, the population included the baseline data AND all the values for 2025, 2055, and 2085. The next step is to return to each of the original time horizon maps for each bioclimatic parameter and calculate the z-value for each location, done here with the (simple) Equation 1:

$\operatorname{Bioclim}_{N}($ date $) z=\left(\operatorname{bioclim}_{N}(\right.$ date $)$ value $-\operatorname{bioclim}_{N}($ all $)$ avg $) / \operatorname{bioclim}_{N}($ all $) s d$

Eq 1

where:

$$
\begin{aligned}
\text { Bioclim }_{\mathrm{N}}= & \text { the } \mathrm{N}^{\text {th }} \text { Bioclimate concern of the } 19 \\
\text { Date }= & 1990,2025,2055 \text { or } 2085 \\
\mathrm{Z}= & \text { the } \mathrm{z} \text {-value for that grid cell } \\
\text { value }= & \text { the input value of that grid cell } \\
\text { (all)avg }= & \text { the average for that Bioclim layer that includes data } \\
& \text { from all four time horizons } \\
\text { (all)sd }= & \text { the Standard Deviation for that Bioclim layer that } \\
& \text { includes data from all four time horizons. }
\end{aligned}
$$

An increment of 127 was added to make this value better fit in the required 0-255 range, to ensure no negative values existed and to make all the means compatible. The final ranges almost always fell into the range of 124 to 130 . Thus the final maps almost always fulfilled all three requirements.* Tests were conducted to see if stretching the 124 to 130 range to 1 to 255 would make any difference in the final results from the Unsupervised Classification program. The test results were the same with or without the stretch so the unstretched data were used for the rest of the analyses

Where the range of raw values was very small, the resultant map might have a conveniently normal distribution, but it was often discontinuous, thus failing the third requirement. Examples of bioclimatic maps that failed the third requirement are:

- Bio3 Isothermality has only 18 levels

- Consecutive Dry Months has only 12 levels.

\footnotetext{
* It is possible but highly unlikely a value below zero or above 255 may exist in the resultant data. To prevent these unlikely events, all values above 255 were assigned to 255; all values below zero were assigned to zero. These extremes however never occurred in the output data
} 
Thus the use of Bio3 and Cons_mths were limited because they met the expectations of a multivariate input very poorly. Tests indicated that the classification programs would still work in spite of this characteristic. This was fortunate because it was suspected that consecutive dry months might become an important ecosystem distinguishing factor.

\subsection{Applying Unsupervised Classification}

Unsupervised classification is a computer-automated MVA method of pattern recognition in which parameters specified by the user are used to group data into statistically separated sets of locations. The result is a set of statistically distinct data "signatures" that can be used to categorize each location, which often results in the creation of a map of statistically distinct patches. This is because typically neighboring locations share similar signatures. Carrying out an Unsupervised Classification consists of two steps: clustering all the data into statistically separate group identifications and then assigning each grid cell to the signature that is most similar to their spectral characteristics.

The clustering algorithm (GRASS Development Team 2012) reads through the raster data and builds sets of locations that share a similar spectral reflectance (see Figure 3). The pixel clusters are imagery categories that can be related to land cover types on the ground. The spectral distributions of the clusters (which will be the land cover spectral signatures) are influenced by parameters set by the user. Parameters include number of resultant classes, sample interval, iterations limit, convergence, cluster separation, and minimum number of pixels for a valid class. In effect, when parameters were set they always tended to decrease the number of resultant classes. This work strived to get as many classes as possible. Therefore the parameters were almost always the default values.

The clustering starts by generating spectral signatures for a number of clusters and by "attempting" to end up with this number of clusters during the clustering process. The cluster spectral signatures that result are composed of cluster means and covariance matrices. The signature file used as input for the second step is the file generated by the clustering routine. 
Figure 3. The clustering algorithm builds pixel clusters (right) based on the spectral reflectance's of the pixels.

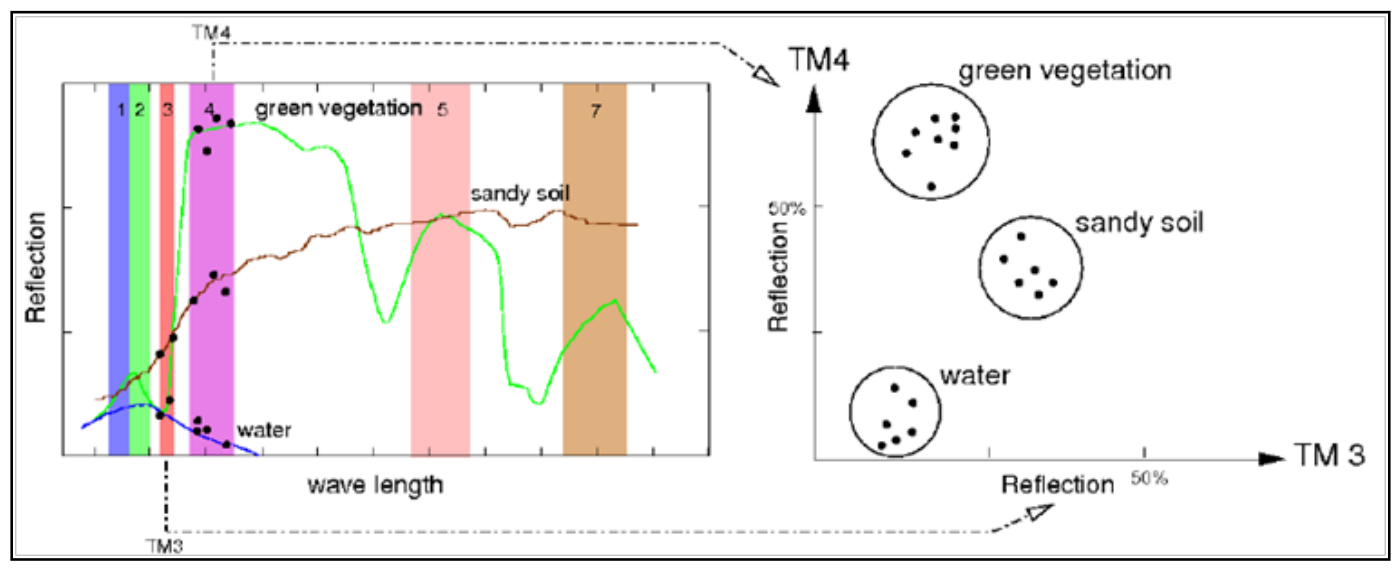

Source: GRASS Development Team (2012).

In the second step, these cluster means and covariance matrices are used to classify all the pixels by separating them into groups on the basis of the maximum likelihood that the individual pixel belongs in a specific group. In this case, the maximum likelihood is equal to the minimum statistical distance from the mean of any of the groups possible. The clusters or spectral classes that result can be related to land cover types on the ground (Figure 3, right). The user has to specify the name of a group, the name of subgroup, and the name of a file that contains the signatures. The subgroup contains only the imagery band files that the user wishes to classify. The discussion below compares the effect that using a different number of bands has on the output resultant map. This research substituted bioclimatic bands for the traditional imagery bands.

As alluded to previously, in the analysis of the bioclimatic data layers transformed into z-values, signatures for clusters were developed by simultaneously analyzing 1990, 2025, 2055, and 2085 datasets. These clusters were then used to categorize each set independently to create a single categorized map for each of the four time frames. This meant that the Category 1 in each map is associated with the same signature, allowing identification of areas that exist today that share characteristics of the future Fort Benning. Running the Unsupervised Classification on the data gave comparable results for the 1990 and 2025 time frames. Analyses were run for 2055 and 2085, but resulted in no patches that were the same as those at Fort Benning in 1990 so no comparisons for these dates can be carried out. 


\subsubsection{Effects of variable layer inputs on unsupervised classifications and class migration}

This section integrates the discussion of the results into a description of the effect of varying the number of input bands or layers in what is basically a sensitivity analysis. The number of bands is being varied to determine if adding more bands produces a better output.

Varying the number of input bands results in a problem in identifying the categories that are the same between submissions. To simplify this and make the discussion relevant, this work focused on what occurred to those classified patches that best characterized the immediate Fort Benning area. It was assumed that a patch located in the same place at the same time in each of the three trials is equivalent between analyses with a different number of input layers. The research question of interest then becomes:

From where in 1990 did the patch that exists at Fort Benning for the period 2025 come?

Using a sample of 30 patches in each time horizon (1990 and 2025) and each multilayer submission $(4,6$, and 8$)$, the characteristics of patch movement like those in Figure 4 were measured. Table 3 lists the averaged values and the results.

Movement in the X (east-west) direction is small. The movement in the $\mathrm{Y}$ (north-south) direction slowly decreases as more layers are added and always varies more than that in the $\mathrm{X}$ direction.

For four layers, two categories dominate the region around Fort Benning in 2025. Category 19 comes from a location in 1990 (in Figure 4 Category 19 is light blue) that is about $130 \mathrm{~km}$ to the southeast of the installation while Category 75 on Fort Benning comes from an original patch (the lighter green) that was $120 \mathrm{~km}$ to the south-southeast of the installation.

Table 3. Cluster migration amounts 1990-2025.

\begin{tabular}{|l|c|c|c|c|c|c|}
\hline & \multicolumn{2}{|c|}{$\begin{array}{c}\text { For 4 Layers } \\
\text { Bios 1, 9, 12, 19 }\end{array}$} & \multicolumn{2}{c|}{$\begin{array}{c}\text { For 6 Layers } \\
\text { Bios 1, 9, 11, 12, 14, 19 }\end{array}$} & \multicolumn{2}{c|}{$\begin{array}{c}\text { For 8 Layers } \\
\text { Bios 2, 9, 11, 12, 13, 14, 19 }\end{array}$} \\
\hline Change in & $\mathrm{x}$ & $\mathrm{y}$ & $\mathrm{x}$ & $\mathrm{y}$ & $\mathrm{x}$ & $\mathrm{y}$ \\
\hline Average $^{*}$ & 5.8 & 12.1 & -3.0 & 7.9 & 0.1 & 5.1 \\
\hline SD & 10.7 & 9.1 & 16.0 & 7.2 & 7.7 & 5.0 \\
\hline "Values are unitless.
\end{tabular}


For six layers, Category 35 dominates southwestern Fort Benning and Category 30 dominates northeastern Fort Benning in 2025. Category 30 comes from a location in 1990 that is about $55 \mathrm{~km}$ to the south of the installation. (In Figure 5, Category 30 in 1990 is light green.) Category 35 on Fort Benning comes from an original patch (the lighter blue) that was 140 $\mathrm{km}$ to the southeast of the installation. This is the effect of the "Benning hole" as predicted.

For eight layers (Figure 6), Category 18 dominates Fort Benning in 2025. Category 18 comes from a location in 1990 that is nearly $100 \mathrm{~km}$ to the south-south east of the installation.

In all three cases, even though a different number of input layers were used, the source of the Fort Benning bioclimatic characterization for 2025 originates in 1990 from about $100 \mathrm{~km}$ to the southeast. This implies that, in 2025, the Fort Benning natural environment will become similar to the 1990 environment in Sasser, GA.

\subsubsection{Ecosystem migration to Fort Benning}

Overlaying a map of ecosystems onto this region shows how the ecosystems will migrate in the Fort Benning region (Figure 7). The installation currently lies at the junction of two major eco-units. Part of Fort Benning (the yellow southwest third) is in the Coastal Plains - Middle Section. The rest of it is in the Gulf Coastal Plains and Flatwoods Section. Figure 7 shows that, from the Forest Service Ecosystem delineation, the location $100 \mathrm{~km}$ to the south-southeast that will migrate to the Fort Benning area by around 2025 will be a combination of the Wiregrass Plains and the Plains Subsections. Although most of Fort Benning is currently at the northern edge of the Gulf Coastal Plains in the Sandhills Subsection, this does not mean that its ecosystem will be changed by 2025 . There will be a lag in the occupying vegetation. 
Figure 4. Four layer clustering results for Fort Benning for 1990-2025.

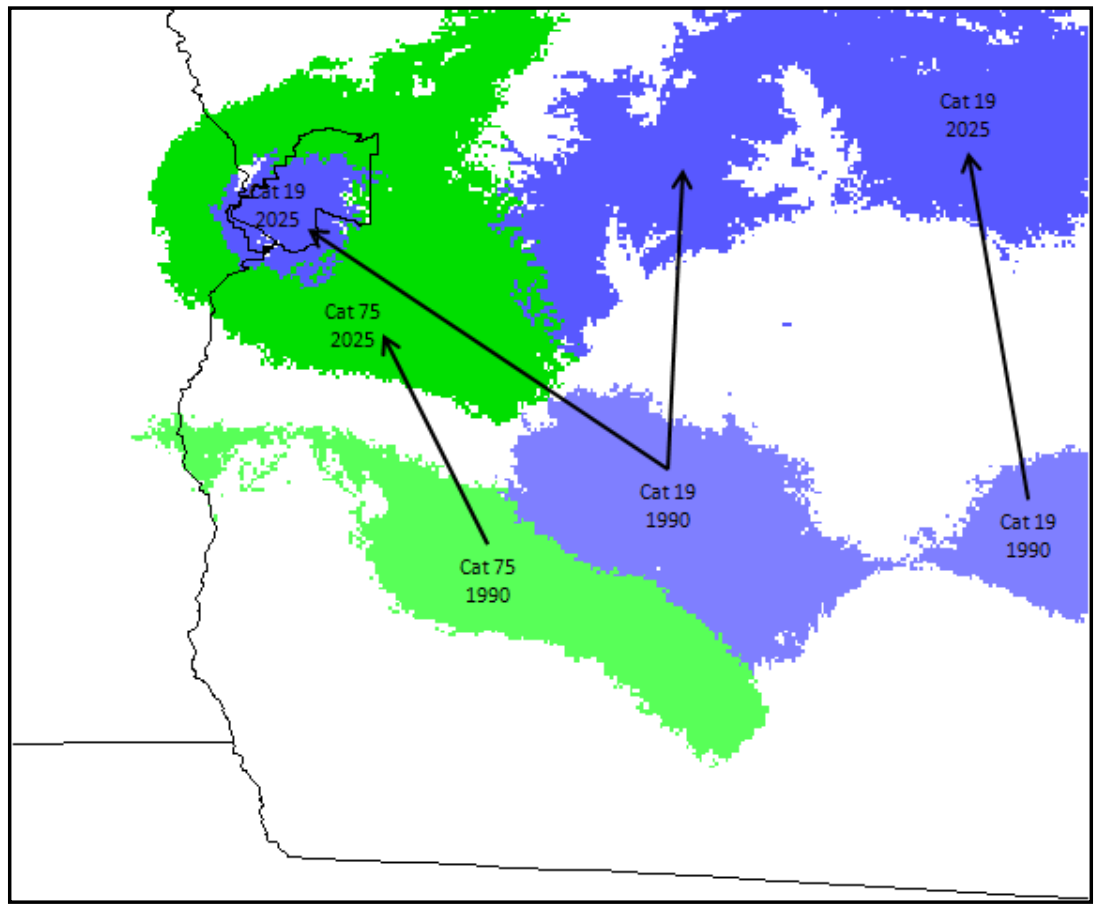

Figure 5. Six layer clustering results for Fort Benning for 1990-2025.

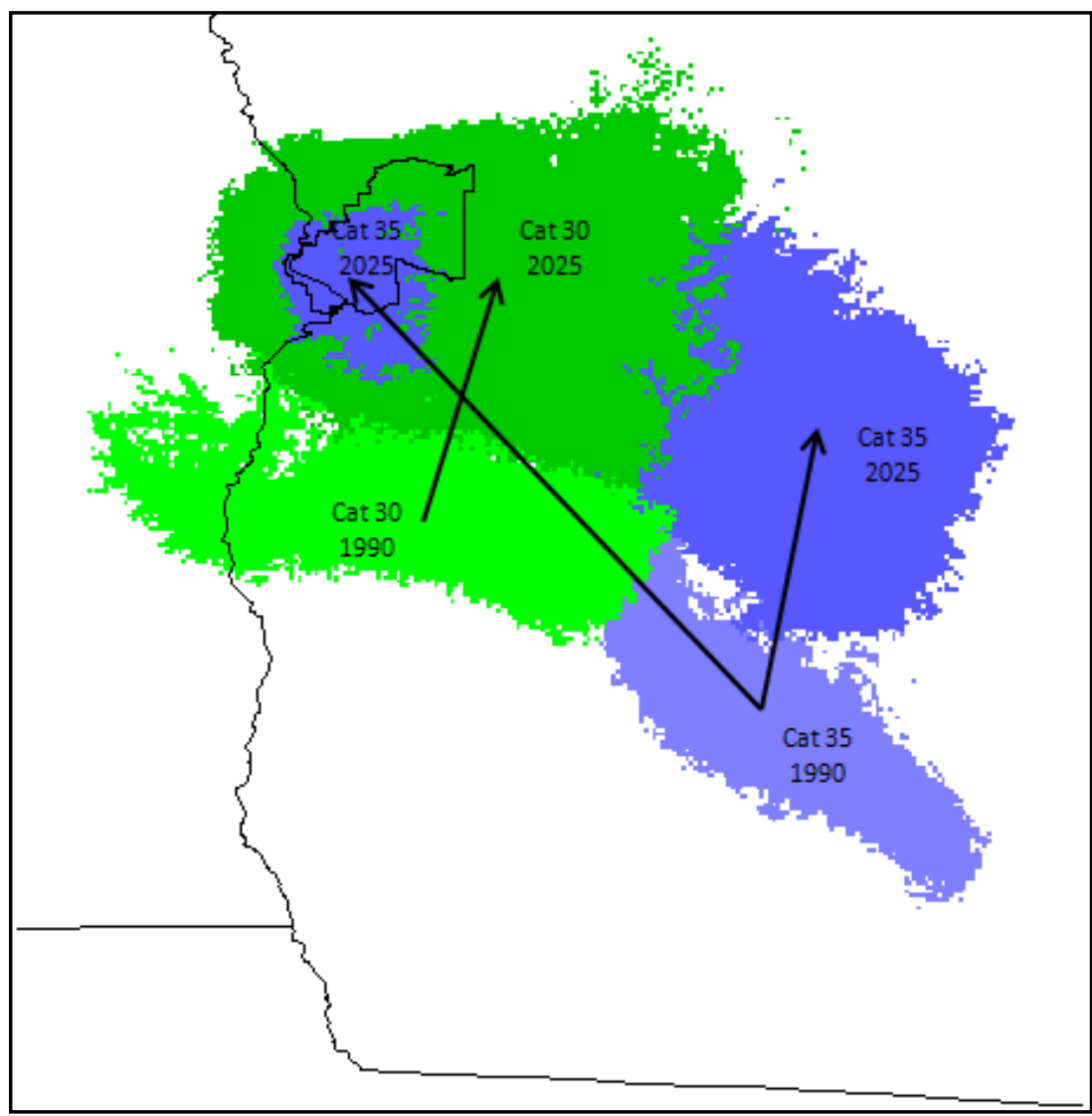


Figure 6. Eight layer clustering results for Fort Benning for 1990-2025

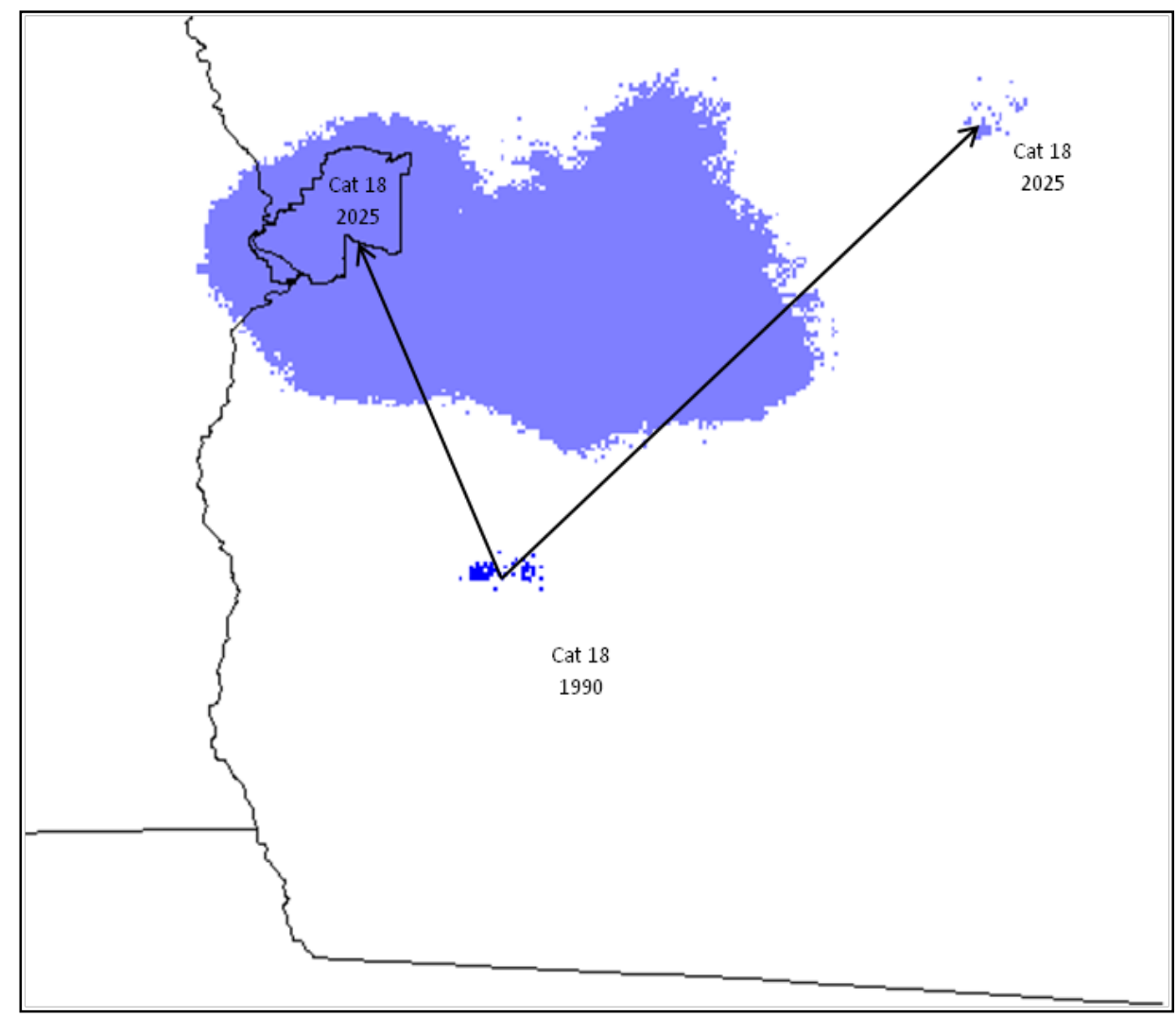

Figure 7. Migration of ecosystems into the Fort Benning region based on the Unsupervised Classification results for 2025.

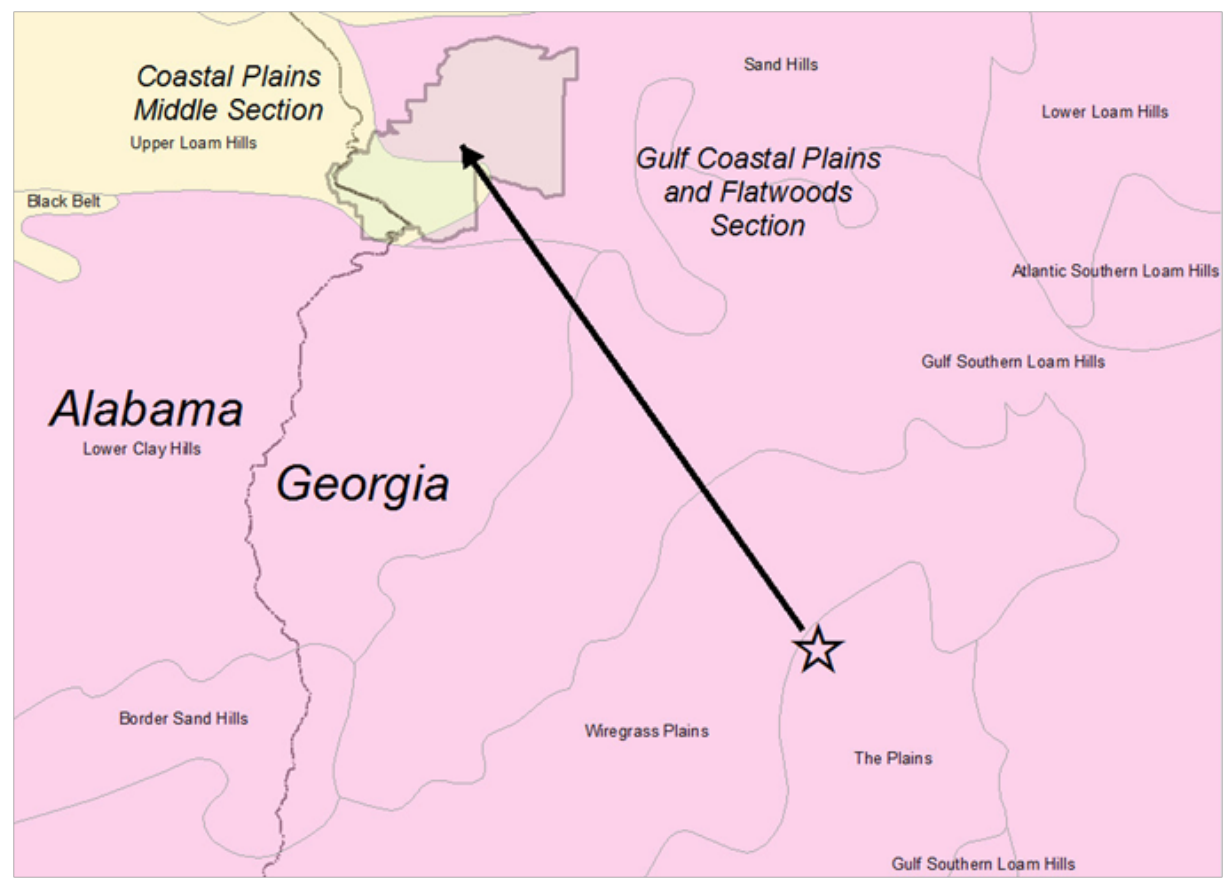


However, it does mean that those climatic parameters that helped to form the Sandhills will have migrated away to be replaced by new parameters that are characteristic of The Plains and Wiregrass Plains areas. That is, Fort Benning's ecosystem will attempt to adapt to climatic forces formerly associated with the Wiregrass Plains and the Plains. Vegetation and maybe fauna will be influenced. Of course the sandy soils of the Sandhills will not migrate. This observation suggests that a new nomenclature for ecosystems must be developed if researchers are actually going to follow their changes in over time.

Table 4 lists some of the differences between the current and future Fort Benning ecosystems. The data in Table 4 make it clear that not only will the ecosystems change, but some of the important ecosystem characteristics will alter. A major change is that expected snowfall will disappear. Snow reflects a great deal of light back into space. Without the snow, that radiation will be absorbed. This will contribute to winter time heating significantly. Along with this, the mean monthly minimum temperature in J anuary will rise from below freezing $\left(32^{\circ} \mathrm{F}\right)$ to above freezing by several degrees. This is important because many plant and animal species cannot survive freezing temperatures. One can expect many more types of invasive species to be able to establish a foothold in the Fort Benning area than would be expected due to a simple rise in temperature of a few degrees. The number of frost-free days will increase significantly so the growing season will be about a month longer. The mean temperature will increase by over 1 degree Fahrenheit and the summer humidity will also increase by 2-3\%. Fort Benning will be warmer in the winter and even more hot and humid in the summer.

It is useful to point out here that the preceding description is not based on the bioclimatic data itself. Instead the data determined the multivariate categories that were then used to find the source location (and therefore ecosystem) that would begin to establish itself at Fort Benning in 2025. The description of the ecosystem at that location in 1990 was then used to characterize the Fort Benning area in 2025. This is a valid but less direct approach to arrive at the same information that could be extracted from the original bioclimatic data. 


\begin{tabular}{|c|c|c|c|c|}
\hline 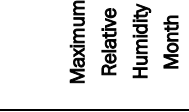 & 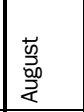 & 入 & ऐ & 言 \\
\hline 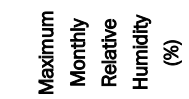 & $\stackrel{m}{\stackrel{m}{\sim}}$ & 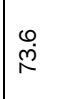 & \begin{tabular}{l}
\multirow{C}{0}{} \\
$\stackrel{0}{0}$
\end{tabular} & \begin{tabular}{|l}
$\infty$ \\
$\stackrel{\infty}{0}$
\end{tabular} \\
\hline 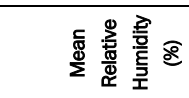 & $\ddot{\wp}$ & \begin{tabular}{|l}
$\infty$ \\
0 \\
0 \\
0
\end{tabular} & 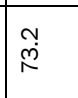 & నె \\
\hline$\frac{\delta}{2}$ & 亨 & ฏ & 全 & ฏ \\
\hline 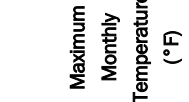 & $\begin{array}{l}\dot{\theta} \\
\dot{8}\end{array}$ & 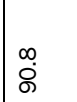 & $\begin{array}{l}0 \\
\text { मे }\end{array}$ & $\begin{array}{l}\infty \\
\text { ने }\end{array}$ \\
\hline 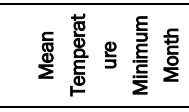 & 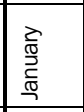 & 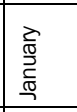 & 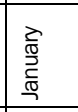 & 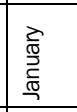 \\
\hline 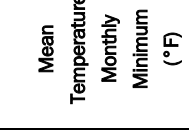 & \begin{tabular}{|l}
0 \\
$\dot{m}$ \\
$\dot{m}$
\end{tabular} & ৪ & $\begin{array}{l}m \\
\dot{e} \\
e\end{array}$ & $\stackrel{m}{\stackrel{m}{m}}$ \\
\hline 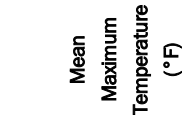 & 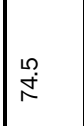 & \begin{tabular}{|l}
$\infty$ \\
\\
\end{tabular} & $\stackrel{0}{\stackrel{0}{i}}$ & 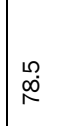 \\
\hline 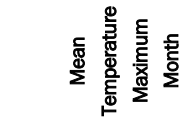 & ऐ & ऐ & ฏ & ฏ \\
\hline 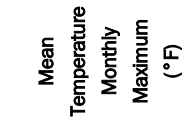 & $\hat{\infty}$ & $\underset{\substack{-1 \\
0}}{0}$ & $\begin{array}{l}\infty \\
0 \\
0\end{array}$ & 竞 \\
\hline 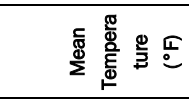 & \begin{tabular}{|l}
$m$ \\
in \\
\end{tabular} & \begin{tabular}{|l}
$\stackrel{\circ}{9}$ \\
$\dot{q}$
\end{tabular} & 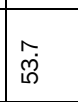 & 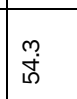 \\
\hline 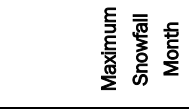 & 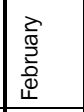 & 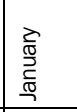 & & \\
\hline 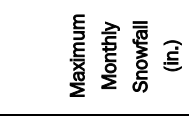 & $\mid \stackrel{n}{\circ}$ & $\ddot{\circ}$ & 0 & 0 \\
\hline 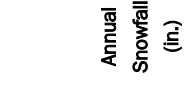 & $\stackrel{\infty}{\infty}$ & ᄀี & 0 & 0 \\
\hline 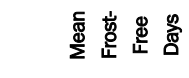 & $\stackrel{\infty}{\text { N }}$ & $\mid \stackrel{\infty}{\text { N }}$ & $\stackrel{m}{\sim}$ & 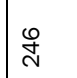 \\
\hline 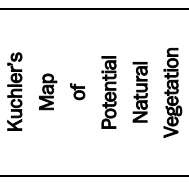 & 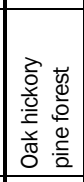 & 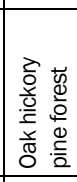 & 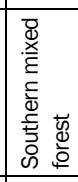 & 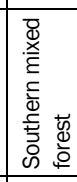 \\
\hline 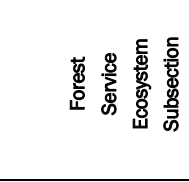 & 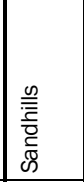 & 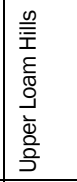 & 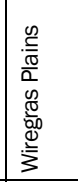 & 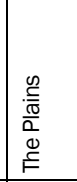 \\
\hline 导 & 吕 & 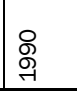 & ڤั & ڤ్ \\
\hline
\end{tabular}


One significant observation is that Fort Benning resides on the northern edge of a major ecosystem division, the Gulf Coastal Plains and Flatwoods Section (versus the Coast Plains Middle Section). Species near the northern boundaries tend to be "hardier" then their relatives in the middle of their range or near the southern edge. As Fort Benning's bioclimatic characteristics change to what is now a more southerly eco-type, those species present will be less stressed so their hardiness can be expected to decrease.

\subsection{The Supervised Classification approach}

In the Supervised Classification approach, the signatures associated with potential classes are based on user identification of the locations of certain areas. When used in association with image processing, the user defines areas by drawing boundaries around the limits of important features. For example, in a satellite image, the user may want to distinguish between soybean and cornfields so he/ she defines a few areas that contain each type. The classifying routine finds the spectral signatures of each type and uses this characterization to find other similar areas. In this case, it was desired to define an area (Fort Benning) and find similar areas over time rather than within the same image.

To carry out this procedure, it was necessary to first define sample locations representing areas of interest in the form of a training map. In this case, the training map was the topographic elevation map reclassified into 57 elevation classes. Many of the climatic concerns mimic and/ or are influenced by topography so using topography was a means to generate marginally related but independent analysis for the training map input. A signature was then calculated for each of these areas, consisting of value mean and standard deviations for each of seven bioclimatic maps (Table 5).

Table 5. Bioclimatic characteristics used in the Supervised Classification analysis.

\begin{tabular}{|l|l|}
\hline Layer & Characteristics \\
\hline Bioclimatic Layer 1 & Annual Mean Temperature \\
\hline Bioclimatic Layer 2 & Mean Diurnal Range (Mean of monthly (max temp -min temp)) \\
\hline Bioclimatic Layer 9 & Mean Temperature of Driest Quarter \\
\hline Bioclimatic Layer 11 & Mean Temperature of Coldest Quarter \\
\hline Bioclimatic Layer 12 & Annual Precipitation \\
\hline Bioclimatic Layer 13 & Precipitation of Wettest Month \\
\hline Bioclimatic Layer 19 & Precipitation of Coldest Quarter \\
\hline
\end{tabular}


Notice that these are not the same layers as used previously. The original intent was to always use the same set of bioclimatic layers as the inputs between the analyses. It was found that success in getting any output varied depending on which layers were used. (Also the number of output categories varied greatly depending on the combinations of inputs used.) This research presents the best outputs obtained. Usually, a large number of input combinations were tested in the process. Even so, as is evident from the discussions, it was often possible to follow a specific category across only a couple time horizons rather than all four.

At this point, it is desirable to identify the current location of the areas that most closely match the conditions anticipated at Fort Benning in 2085. The established signatures were applied to the set of maps associated with 2085 using a maximum likelihood classifier and it was discovered that Fort Benning is associated with a single signature (Category 16 shown in Figure 8a). Applying the signature set to the suite of 2055 (Figure 8b), 2025 (Figure 8c), and current maps (Figure 8d) allows identification of the areas that are assigned to Category 16 . The last lower right quadrant of the image identifies where one might go today to experience the bioclimatic conditions anticipated in 2085.

Figure 8 shows that there is a march of similar areas (in blue) moving to the north to Fort Benning. In fact, it is easier to understand these results in reverse order - in the last image (1990) the 2085 climate exists just north of the Florida Panhandle state line. As time passes, the areas similar to the 2085 characterization slowly march roughly north and west to finally be at Fort Benning's location by 2085. The analysis results for 2025 are similar to those previously found using the Unsupervised Classification approach described in Section 4.3.1. (The unsupervised analysis produced no results for 2055 or 2085 that could be used for comparison with these.)

\subsection{The principal components analysis}

Principal Components Analysis (PCA) is a method of data compression that allows less redundant data to be expressed in lower band numbers. For example, if a user inputs four bands (normally spectral imagery bands), the classification routine will output four new bands. 
Figure 8. Supervised classification Category 16 that represents Fort Benning in the 2085 period (upper left), the 2055 period (upper right), the 2025 period (lower left), and the 1990 period (lower right).

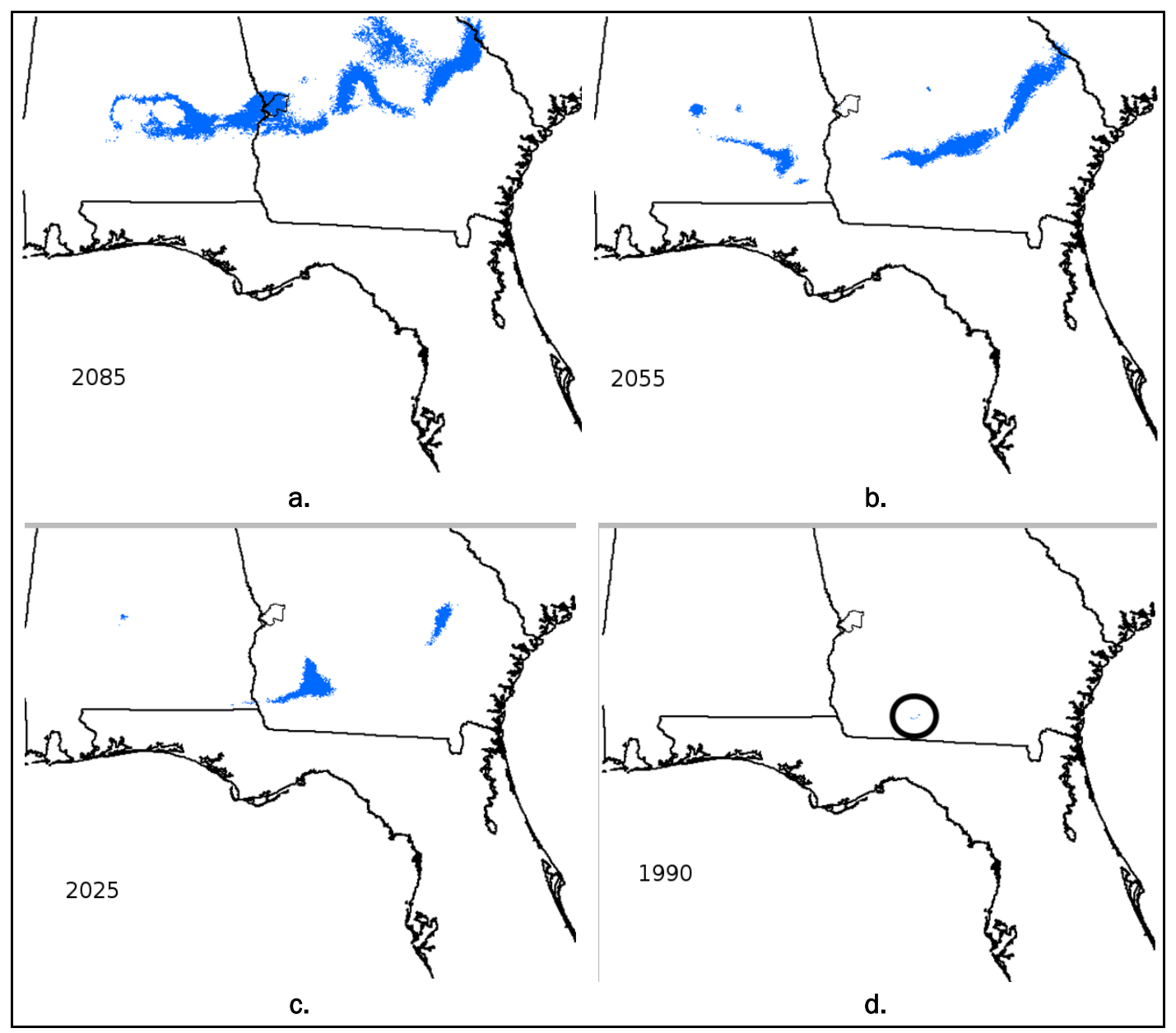

These new bands will have their axes mathematically twisted so a scatter plot of the bands of data represent the widest variance among the data in the first band and each successive axis (band) represents the next smaller amount of variance that is not already represented. Principal components axes are orthogonal (perpendicular) to one another. Principal component bands are uncorrelated and nonredundant since each principal component describes different variance within the original data.

The drawback in using the traditional Unsupervised Classification technique is that, if the underlying variance matrices were poorly formed, then the maximum likelihood classifier would not run or it would generate only a few classes. Furthermore, as has been mentioned, some of the bioclimatic datasets seem to be highly related so that those that are "repeated" are given extra weight in the final analysis. A PCA realigns the 
data axes so that most of the variance in the data is along the first axis, the next axis is oriented orthogonally along the direction of the next highest variance direction, etc. for all further axes generated. This means that most of the data information is located in the first few layers generated and that the variance matrices are well formed for use by the maximum likelihood classifier. PCA groups are created by forming composite axes that maximize the overall distance between the data. In other words, PCA determines the net effect of each variable on the total variance of the dataset, and then extracts the maximum variance possible from the data. Normality in the distribution of variables is not strictly required, but it does enhance the analysis. It was decided to apply the PCA to the issue of climate change at Fort Benning.

As a quick check of these assumptions, a small test study area slightly larger than Fort Benning was selected. The basic procedure was applied using four precipitation bioclimatic layers and four temperature bioclimatic layers of the 1990 bioclimatic data. The resulting PCA output had eight layers. Figure 9 shows the first four components of the eight generated. Figure 9a shows the PCA output axis 1 (67\% of the variance), which is an integration of topography along with precipitation. The two brightest areas (upper center left and right edge) coordinate with precipitation low districts. These can have influence in the classification results. Figure $9 \mathrm{~b}$ shows Axis 2 ( $22 \%$ of the variance), in which a progression can be seen from upper left to lower middle with topography barely indicated. Figure 9c shows Axis 3 ( $6 \%$ of the variance), which is a very similar progression without the topography. Figure 9d shows Axis 4 ( $3 \%$ of the variance), which exhibits a hyperbolic distribution not clearly attributable to any characteristic. These illustrate both the PCA method of handling data and some of the attributes inherent within the data itself.

All eight PCA output layers were run through the clustering and the maximum likelihood classifier. The all 8-layer analysis generated 147 classes ( $100 \%$ of data value used). When the analysis was run with only the first four layers (which contained $98 \%$ of the variance) all of the PCA layers were found to be acceptable to the maximum likelihood classifier. The 4-layer analysis generated 153 classes. In all cases the distribution of patches is similar except that the 4-layer analysis was better defined while the 8-layer analysis was more "speckled." 
Figure 9. First four components of the eight generated by the PCA for 1990. Axis 1 is upper left, Axis 2 is upper right, Axix 3 is lower left, Axis 4 is lower right

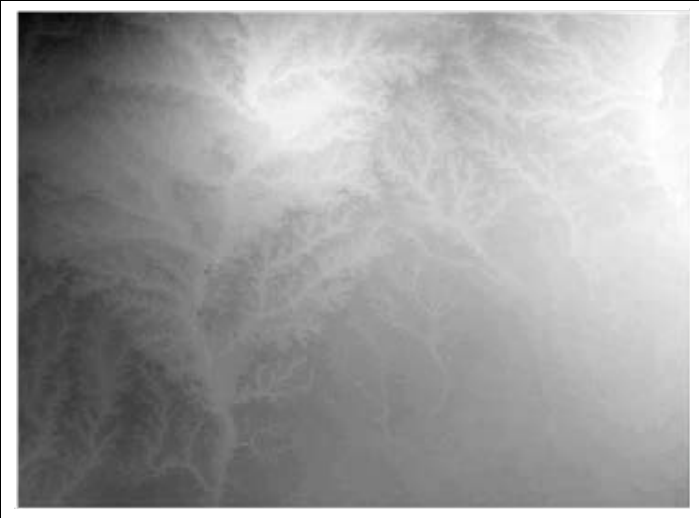

a.

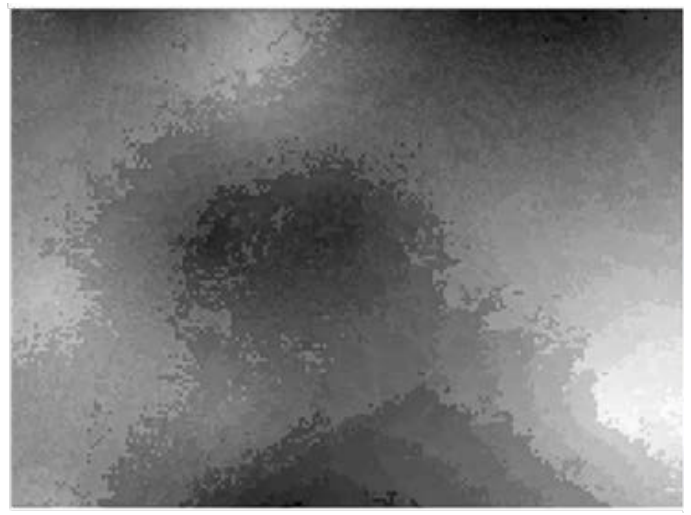

c.

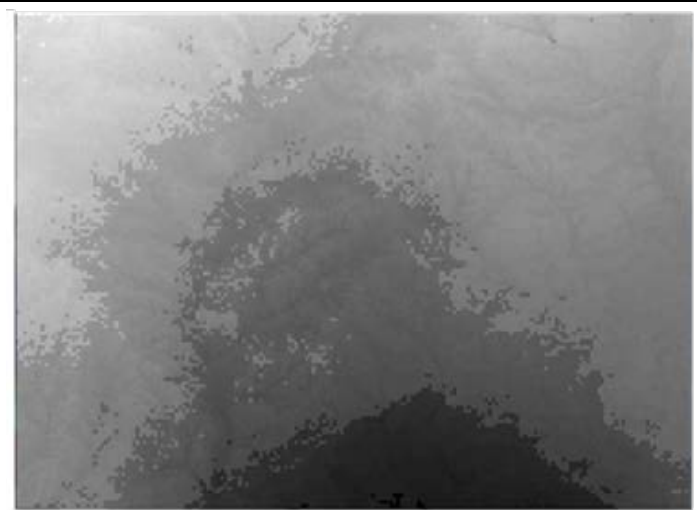

b.

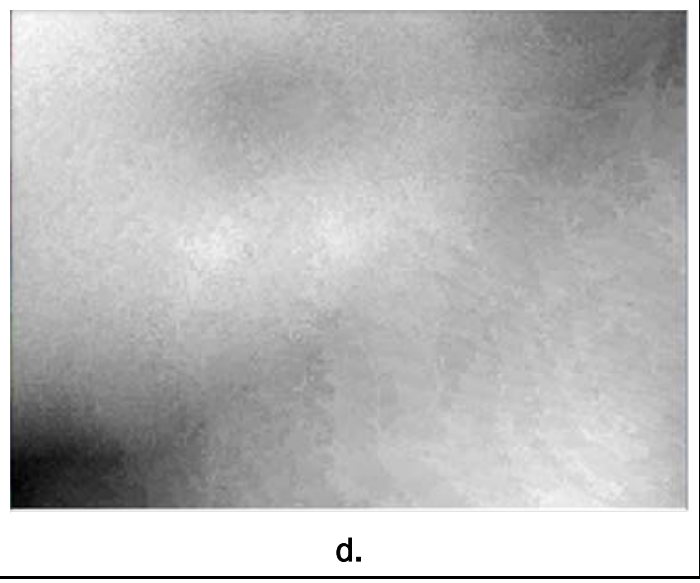

Two more analyses were done. The 3-layer classification (containing 95\% of the variance) generated 154 classes. The 2-layer classification (containing $90 \%$ of the variance) generated 150 classes. The 2-layer analysis was strikingly similar to the yearly precipitation data hole shown in Figure 1 ( $p$ 9). As more data are added, the domination of precipitation becomes less noticeable. Interesting, the borders of the classes generated in the outputs only mildly suggest any topographic influence although PCA output Layer 1 above (Figure 9b) seems to be predominately topography. One interpretation of this is that phenomenon is that adding further increments of less important information to the analysis only tends to confuse the result. The results of this test suggested that carrying out the full analysis would result in an improved output.

Running the PCA on the entire study area for all 19 bioclimatic layers for all four time periods resulted in a transformation in which the first two layers accounted for close to $100 \%$ of the variance in the original data. 
Thus for the next step, the clustering routine, it was only necessary to use these two bands to account for nearly all the information value.

After applying the Unsupervised Classification procedure (the clustering and maximum likelihood analyses) to the PCA bands, 91 categories were defined in the output results. Figure 10 shows those classes that occurred within Fort Benning in the 1990 time horizon. As can be seen, Fort Benning is located at the western end of a band of similar classes that stretch to the east and then north parallel to the Atlantic coast. In fact, this area coordinates closely with the Forest Services' ecosystem delineation of the northern edge of the Southern Atlantic Coastal Plains and Flatwoods Section within the Province type of Outer Coastal Plain Mixed Forest.

Figure 11 shows those patches that by 2025 will move to Fort Benning. Again the darker areas show greater occurrence on the installation. It is notable that the darkest areas (those most common on Fort Benning in 2025) are tending to move further from the east by about $100 \mathrm{~km}$. J ust a small amount of these classes still exist on the installation.

Figure 10. PCA resultant classes that occurred within Fort Benning in the 1990 time horizon (the darker the grey, the more commonly it occurred on the installation).

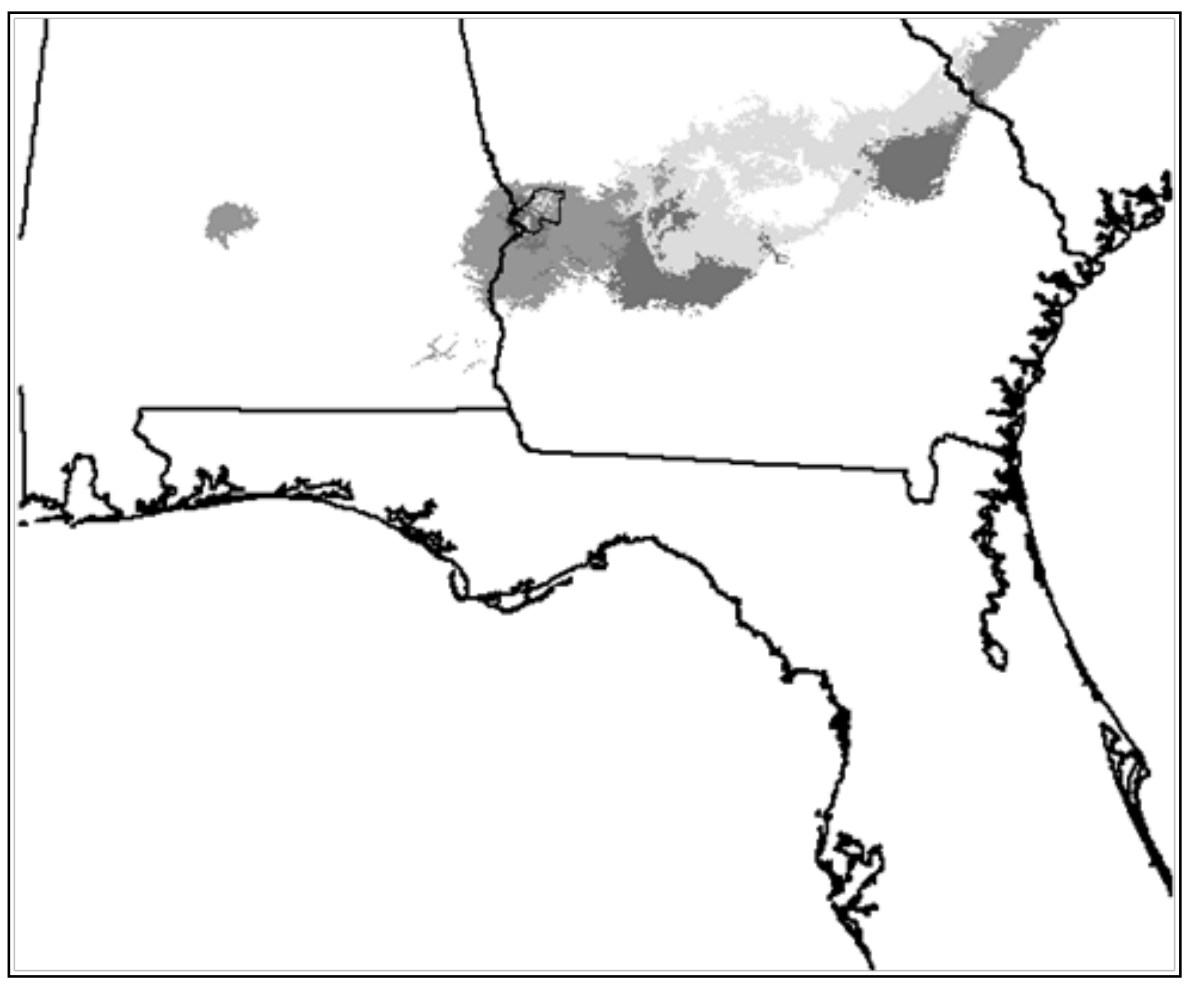


Figure 11. PCA resultant classes that occurred within Fort Benning in the 2025 time horizon.

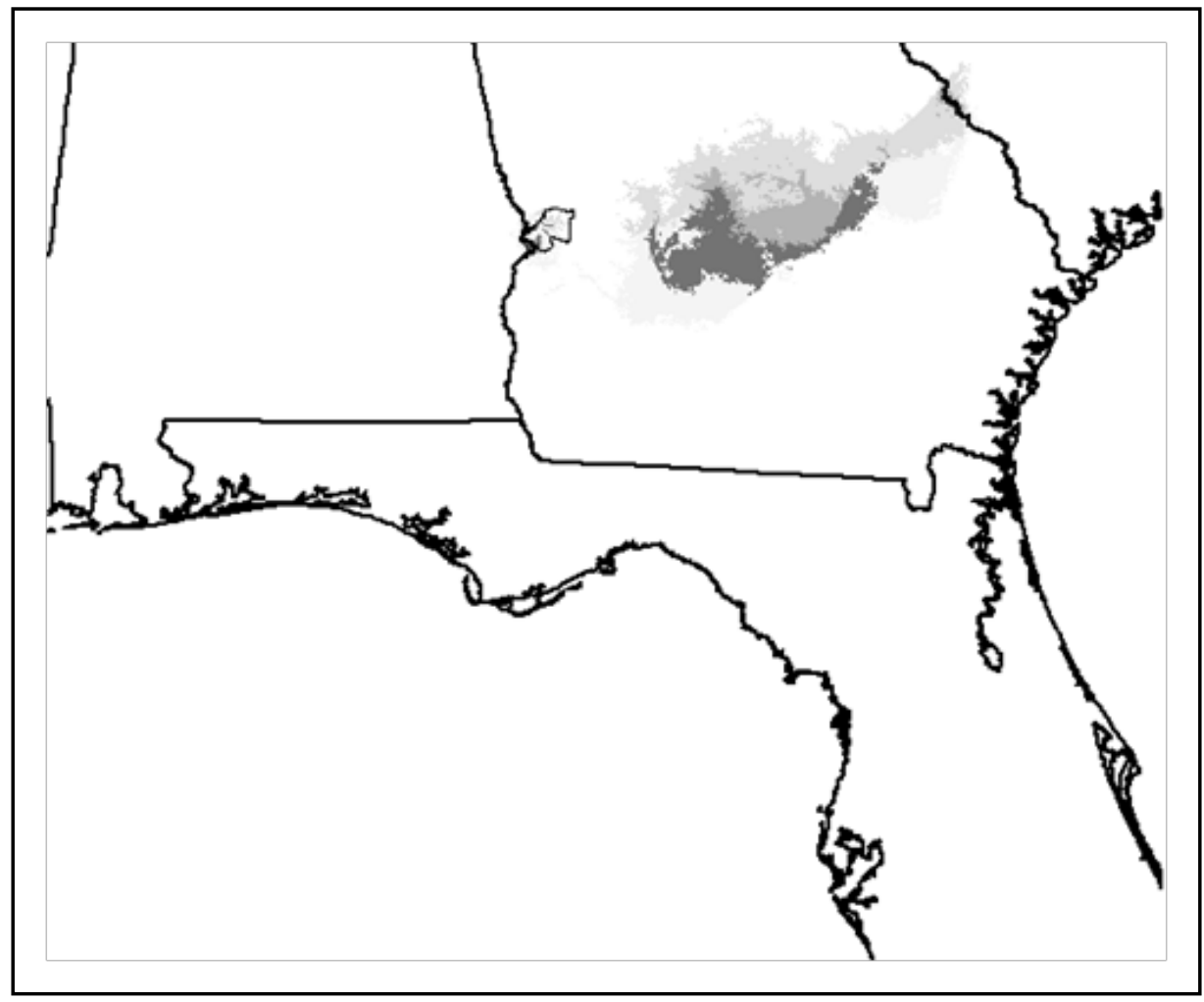

This result is similar to the Unsupervised Classification of Figures 4 and 5 that show categories 19 and 35 (respectively) in 1990 migrating to Fort Benning by 2025.

The most common class on Fort Benning for years 2055 and 2085 does not exist in the 1990 data layer, so it is not possible to show where the 2055 and 2085 classes come from in the 1990 data. It is worth noting that the analysis by Unsupervised Classification also did not generate classes in 2055 and 2085 that could be followed in the 1990 time frame.

\subsection{The Principally Analogous Multivariate (PAM) approach}

\subsubsection{Introduction to the PAM approach}

Most of the MVAs previously presented are based on the classical well documented ISODATA clustering technique from the Unsupervised Classification method (Ball 1965, J ensen 1996, Duda 2001). In carrying out the previous approaches, the research question matured as:

If a similar region to Fort Benning was not identified in the time period 2055, what happened to it? 
In those techniques that failed to identify a similar patch in 2055, it did not seem reasonable to conclude that the patch simply vanished; nor did it seem reasonable to conclude that an analogous patch did not exist. It must exist somewhere, but some of the other MVA techniques were restricted by the mathematical procedure, such that they could not identify what the user wanted to know. The Supervised Classification technique did produce usable results, apparently because the user in that situation had more control over the process. In other words, the user provided a training sample focused on identifying characteristics that would produce given results, to then see if those results would better fit the question. Similarly, this work sought a more direct means to "let the system know" that the results of interest were Fort Benning climate migration.

A more straightforward technique to achieve this result is the PAM approach. This technique calculates the z-score maps for each of the 19 bioclimatic concerns (as before). Once the mean of an area of interest (in this case Fort Benning) is determined, this mean is then subtracted from the bioclimatic map of interest. The smaller the resultant value, the more similar the ensuing areas are to Fort Benning. If you add up all the resultant bioclimatic maps, then the smaller the output value, the more analogous areas are in a 19-dimensional bioclimatic space. Unlike the previous procedures, this technique does not define similar locations; instead it defines most analogous locations. The distinction is that a similar location may not exist, but by definition, a most analogous location will always exist. The advantage of this procedure is that it ensures an analogous location in every time horizon. PAM makes no a priori assumptions about or requirements on the input data. Within the results are also contained a rating of the degree of analogousness rather than a simple identification of belonging to a specific class as in the other techniques.*

A comparable method has been applied to ecosystem migration for military installations (Westervelt 2011). In that analysis the multidimensional distance between the target signature (representing the future state) and the signature at each location in the "current" data was

\footnotetext{
* Some software packages allow another map output (called the threshold map) that does rate the degree that each particular cell belongs to its assigned class.
} 
calculated. A grey-scale-like color table was used to show the results. The darker areas represented more similar locations.

\subsubsection{Applying the PAM approach at Fort Benning}

When applied to for the Fort Benning study area for the 1990 time horizon, this procedure results in a 19-dimensional bioclimatic map (Figure 12a). The darker the area, the more analogous that location is to Fort Benning. Fortunately, Fort Benning presents as the darkest location while a patch to the east is also comparable, but nowhere else in 1990. Applying the same procedure with the same medians to the similar data for 2025 produces slightly different results (Figure 12b), for 2055 (Figure 12c) and for 2085 (Figure 12d).

These analyses show that the current bioclimatic area at Benning will slowly migrate about $210 \mathrm{~km}$ to the north east over the next 90 years. The objective of this research is the reverse question:

From where does the future bioclimatic character of Fort Benning come?

The same technique, modified to address this query, generates a slightly different set of images (Figure 13).

In this series it can be seen that the bioclimatic parameters that move into Fort Benning come from a region about $56 \mathrm{~km}$ southeast of the installation in 2025, then about $93 \mathrm{~km}$ south in 2055 and finally $138 \mathrm{~km}$ south in 2085. It is interesting to note that the area analogous to Fort Benning in 1990 to its east switches sides to the west in the 2055 and 2085 images. In fact, the analogous area in 2085 in central Mississippi is just as strongly related to Fort Benning as is the patch to the south. This suggests that there are possibly two bioclimatic gradients: one marches from south to north, the other from east to west. The east-to west-march also corresponds with the results shown in Figure 12, which indicate that Fort Benning's current climate will relocate toward the east. Also, invasive species that might be a problem to Fort Benning are equally likely to come from south-central Mississippi as from southwest Georgia. 
Figure 12. The 19-dimensional bioclimatic PAM analysis for the Fort Benning study area. These analyses represent the migration of the climate away from the installation. The darker the area, the more analogous that location is to Fort Benning. The time horizons are: $a=1990, b=2025, c=2055$, and $d=2085$.

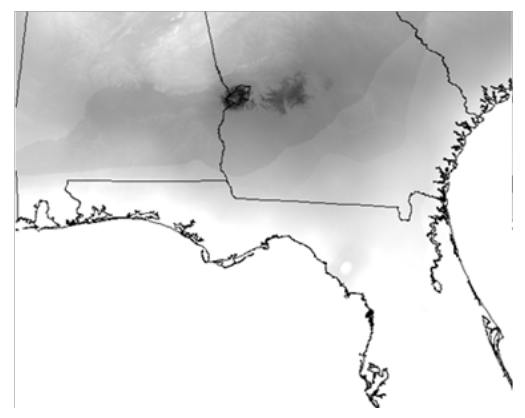

a.

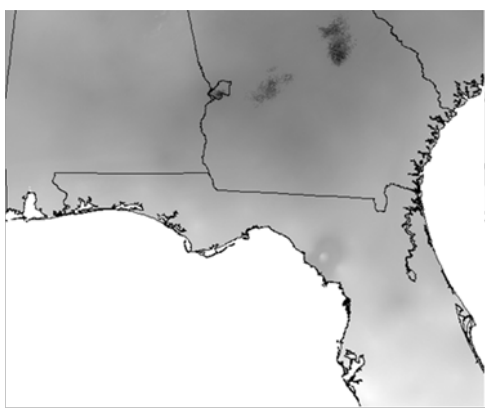

c.

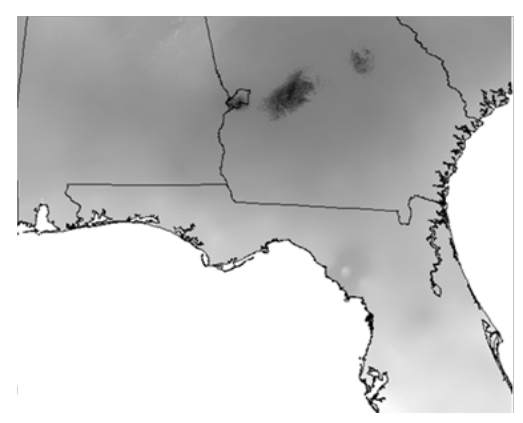

b.

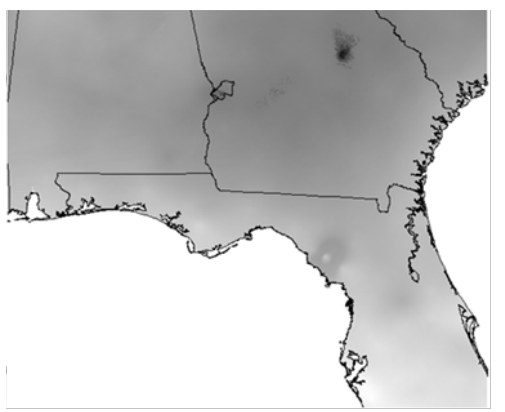

d.

Figure 13. Locations from "where the future bioclimatic character of Fort Benning come." The time horizons are: $a=1990, b=2025, c=2055$, and $d=2085$.

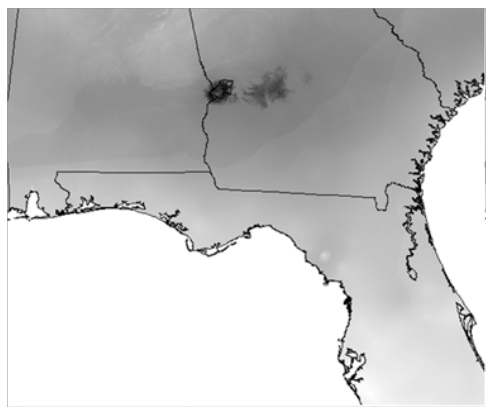

a.

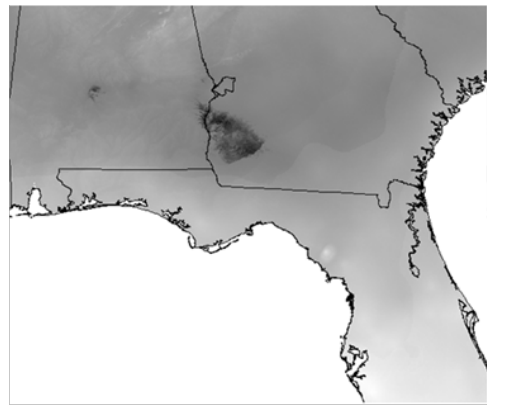

c.

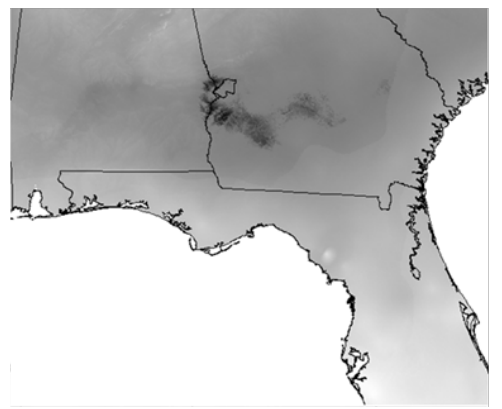

b.

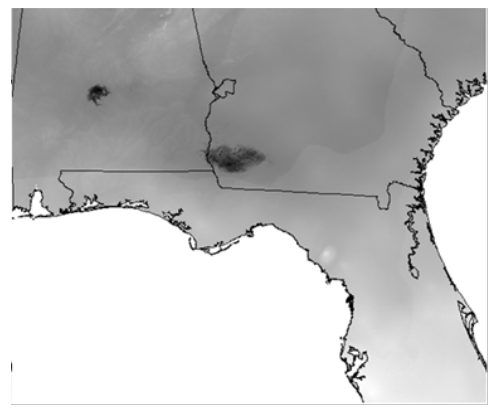

d. 
The Eufaula National Wildlife Refuge (Figure 14) lies about $50 \mathrm{~km}$ to the south of the installation and falls within some of the patches that migrate north to Fort Benning as just discussed. By 2025 the climate around Fort Benning will be tending to look like what is currently within the refuge. A healthy, growing population of threatened American alligators exists in refuge wetlands (USFWS Undated). Resident wildlife, including bobwhite quail, wild turkey, beaver, fox, raccoon, opossum, bobcat, swamp and cottontail rabbits, and white-tailed deer are present in high numbers.

The northerly migration of the bioclimatic concerns suggest that in the next period, about 2115 (for which data were unavailable), Fort Benning's climate will mimic a location in the Florida Panhandle that is occasionally called the Gulf Coast Sandhills. At that time period, not only will the climate be similar, but the soil character will also be similar. Therefore about the year 2115, invasives from the Florida Panhandle will be highly capable of taking up their residence at Fort Benning.

Figure 14. Upland landscape near the entrance to the Eufaula National Wildlife Refuge.

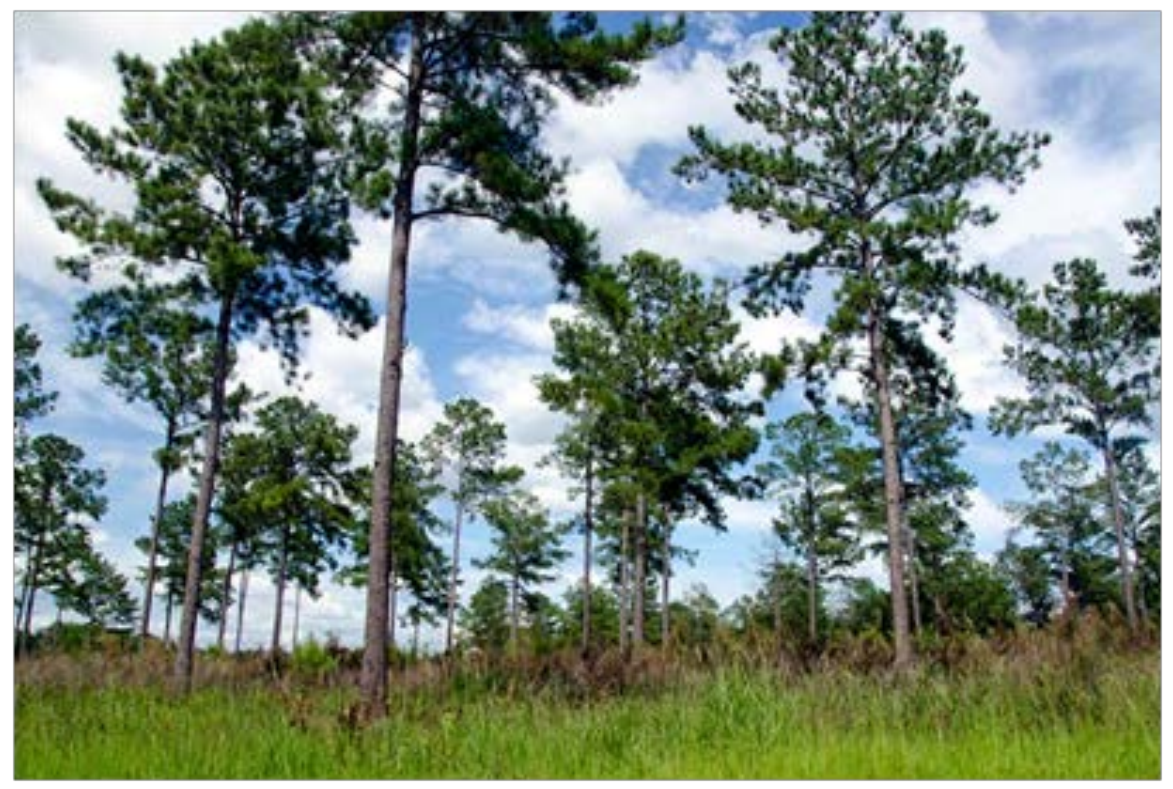


The data in Table 6 outline the characteristics of these regions for each of the time periods. Table 6 lists the values and amount of change that can be extracted from the areas defined above for each of the 19 bioclimatic concerns. This data answers the research question posed at the outset of the report, i.e., What will the climatic factors in the future be at the installation?" A similar table could be generated from the Supervised Classification technique, but not the Unsupervised Classification or Principal Components because they did not generate results that could be followed in 2055 and 2085.

\subsubsection{Migration of Fort Benning forest types - lowlands}

During the late 1990s, the Fort Benning Land Management Branch compiled a digital Forest Inventory map of the forest types at the installation. This map provides a snapshot of the woodland distributions at roughly the time (the late 1990s) as the base climate data (1990). It would be useful if it were possible to use this map and a method similar to the PAM analysis in the last section to follow the location of incoming bioclimatic changes to Fort Benning. The map is used to find the bioclimatic parameters for just the tree types rather than the entire installation. This set of parameters is then applied to the temporal data to follow changes over time. First the inventory was used to generalize the species into less than a dozen major types (Figure 15). That inventory was narrowed into just those wetland types (blue) within a circle centered on the Lower Upatoi Creek that crosses Fort Benning's northwest quarter (also Figure 15). The result (Figure 16) shows the 1990 bioclimatic distribution of cells that coordinate closely with the lowland tree species similar to the Lower Upatoi Creek.

Some sensitivity tests were carried out on the results. First, the median values were generated at the resolution of the forest inventory (0:00:00.323629 degree or 10 meters) and the map generated. Then the median values were developed at the bioclimatic data resolution (0:00:30 degree or about 925 meters) and the map was generated. 


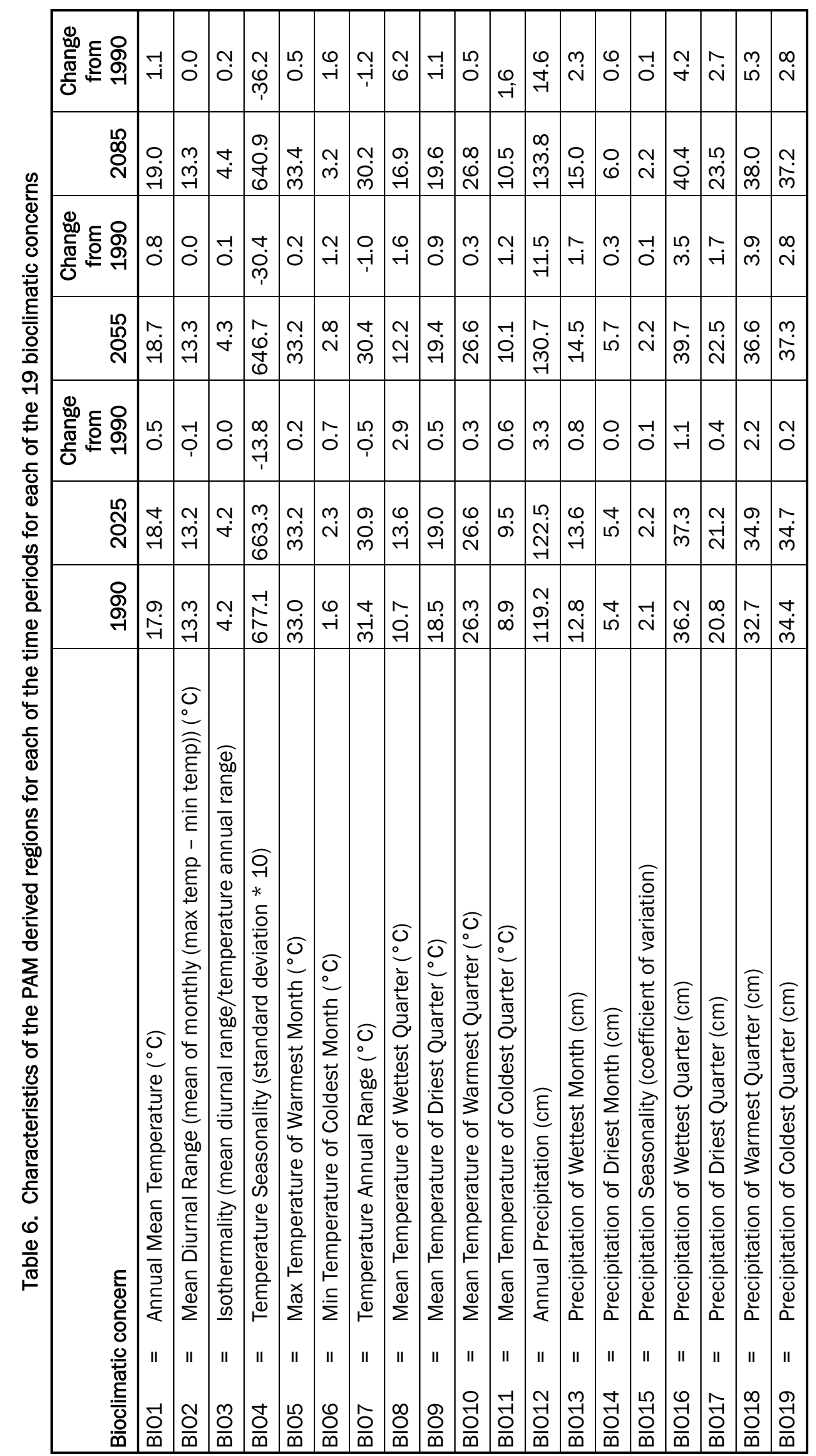


Figure 15. Generalize species from the Fort Benning Forest Inventory map. Wetland types are in blue. The target areas are the blue within the circle centered on the Lower Upatoi Creek.

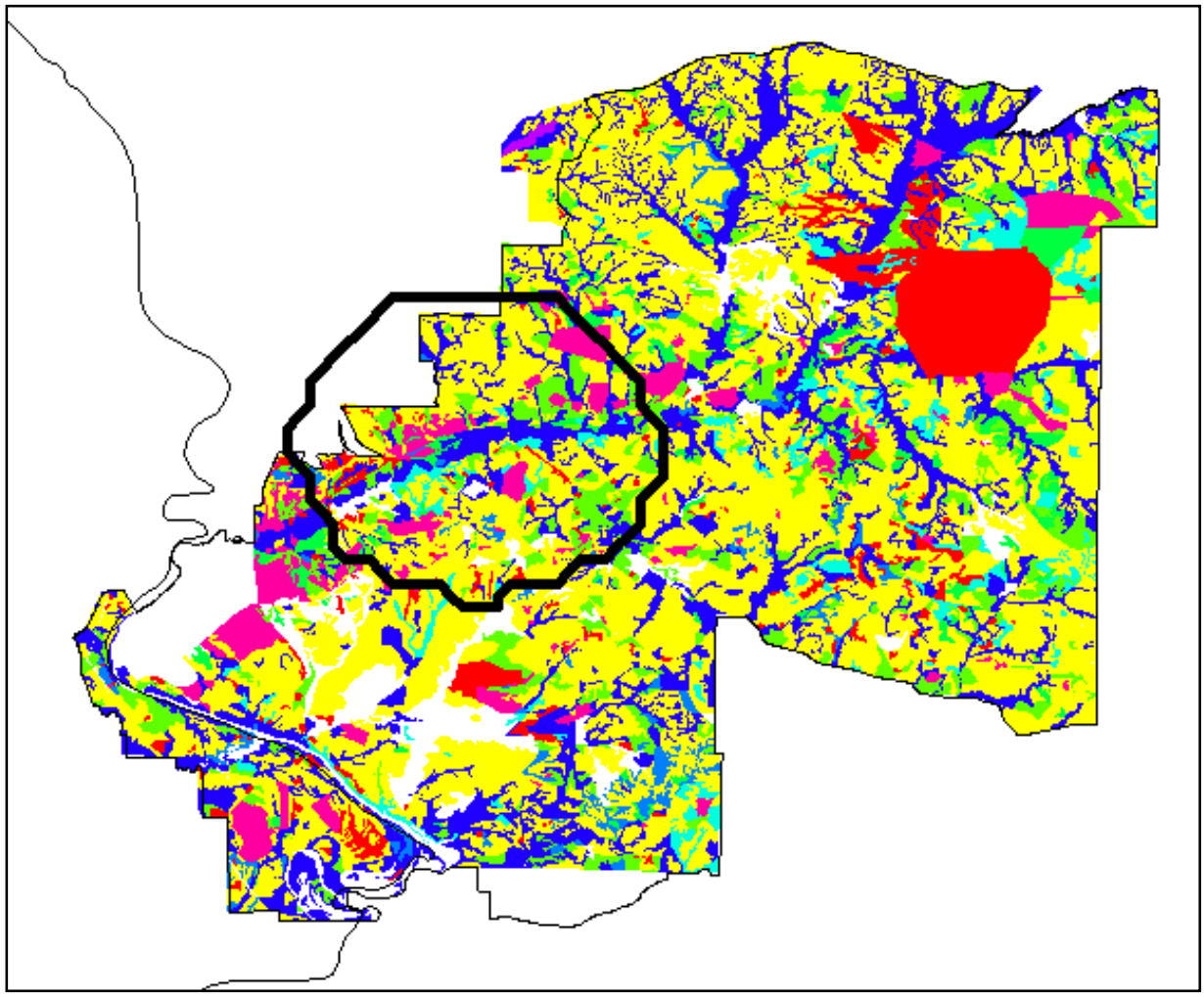

Figure 16. The 1990 bioclimatic distribution of cells that coordinate closely with the lowland tree species similar to the Lower Upatoi Creek from Fig. 25.

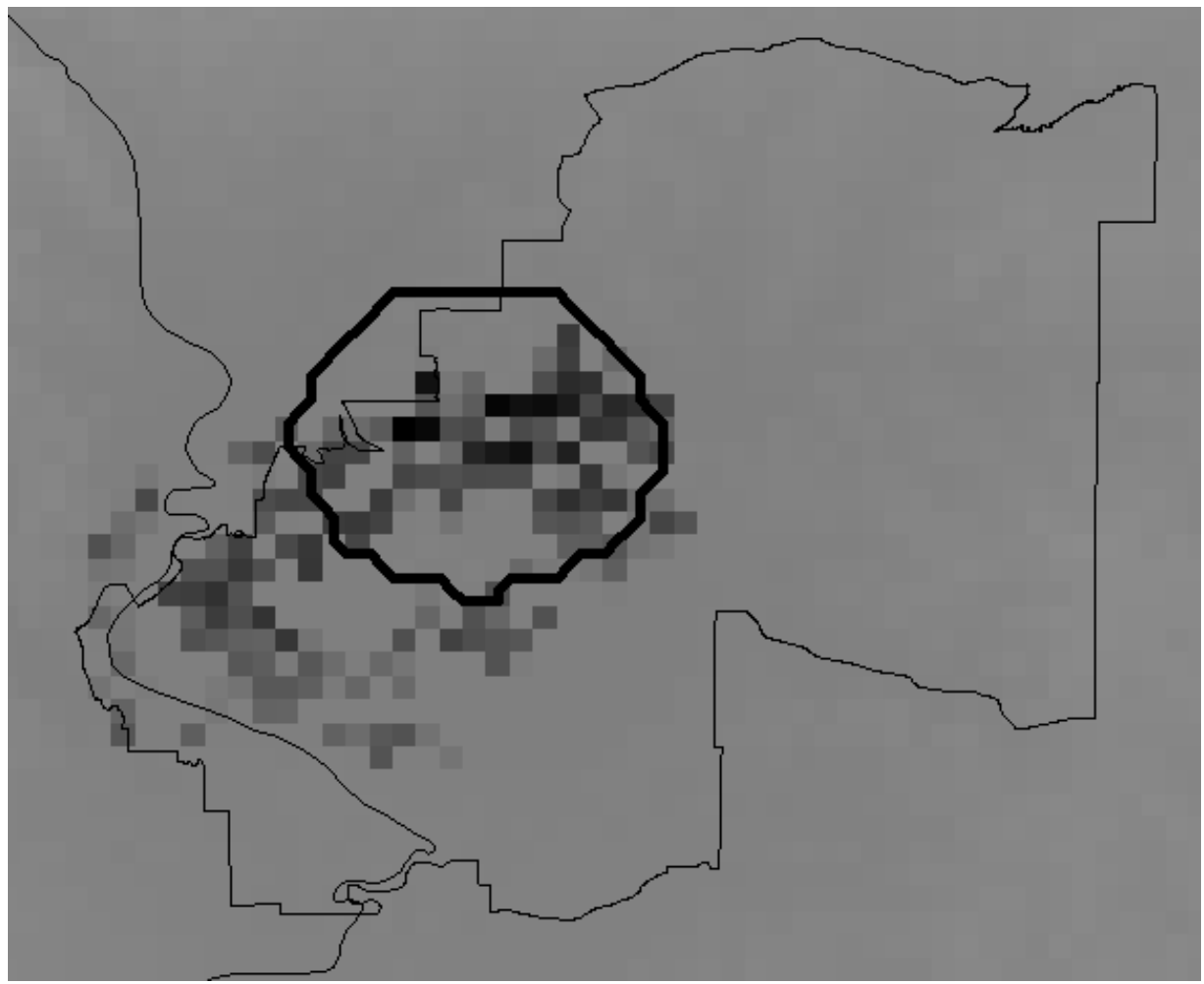


Although the median values varied slightly, the resultant cells chosen were almost the same. In another set of tests, a small constant was subtracted from all 19 median values. (Mean values all varied slightly about the value 127.) There was no change if the constant subtracted was 0.001 , but an entirely different result was obtained when the constant subtracted reached 0.005 . Thus the result is not highly sensitive to changes of resolution, but can be greatly altered by changing of the mean values by as little as $0.004 \%$.

The PAM analysis was applied to the different time horizons. Figure 17 shows the resultant situation for 2025. The darker grey areas show all of the distribution previously chosen for all of the installation (as shown in Figure 13b) while the lighter grey areas show just the lowlands chosen in this analysis. The lighter areas clearly tend to congregate about lowlands, either along the Chattahoochee River or particularly along the ravines in the Lumpkin region about $50 \mathrm{~km}$ to the south of Fort Benning.

Next the analysis was constrained by integrating the geomorphology. The enhanced algorithm penalized upland locations (using a geomorphology dataset generated from a topography data layer with a higher resolution than the bioclimatic data). Figure 17b integrates the geomorphology to refine the analysis. In this case, the algorithm provides a bias to areas that are bioclimatically appropriate and also lowlands. Henceforth in this section, all graphics will show the results with the geomorphology integrated into the image.

By 2055 (Figure 18), all of the lowland habitat on the Chattahoochee west of Fort Benning has disappeared, the prime Lumpkin locations $50 \mathrm{~km}$ to the south remain and the areas $120 \mathrm{~km}$ to the southeast near Albany are much more prominent. The two major locations from which the lowland vegetation will come (the Chattahoochee and the upper Hodchodkee and Pataula Creek areas) are largely the same in 2025 as in 2055 with the caveat that they move south by a few kilometers in both cases.

In about 2085, the prime areas will have migrated even further south, to near the Florida state line (Figure 19). Although these areas still tend to follow the lower neighborhood, at this time period, some inter-ravine areas are also included. This region represents a topographic character that is less well defined; therefore the landform constraints are less clear. The most prominent focus is no longer near the Chattahoochee River, but along the Flint River and Spring Creek to the east of the Chattahoochee. 
Figure 17. PAM analysis for the distribution of lowland tree vegetation change in 2025. Right: The darker grey areas show all of distribution previously chosen for all of the installation (as shown in Fig. 13, upper right) while the lighter grey areas show just the lowlands chosen in this analysis. (All further graphics in this section will use this convention.) Left: Same analysis with geomorphology integrated into the result.

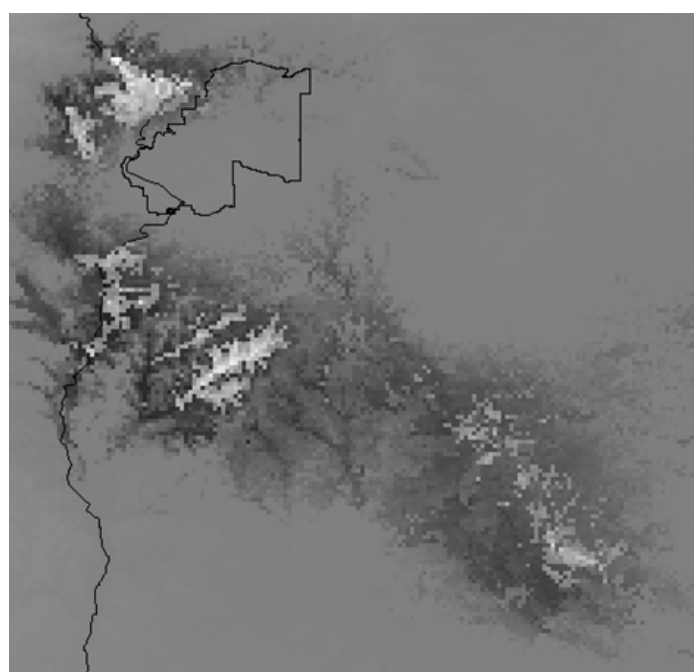

a.

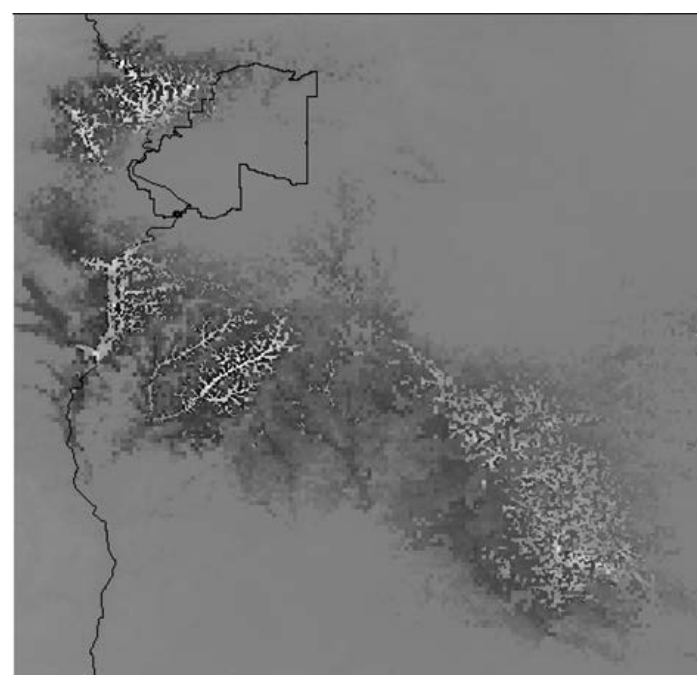

b.

Figure 18. Lowland climate source for Fort Benning in 2055.

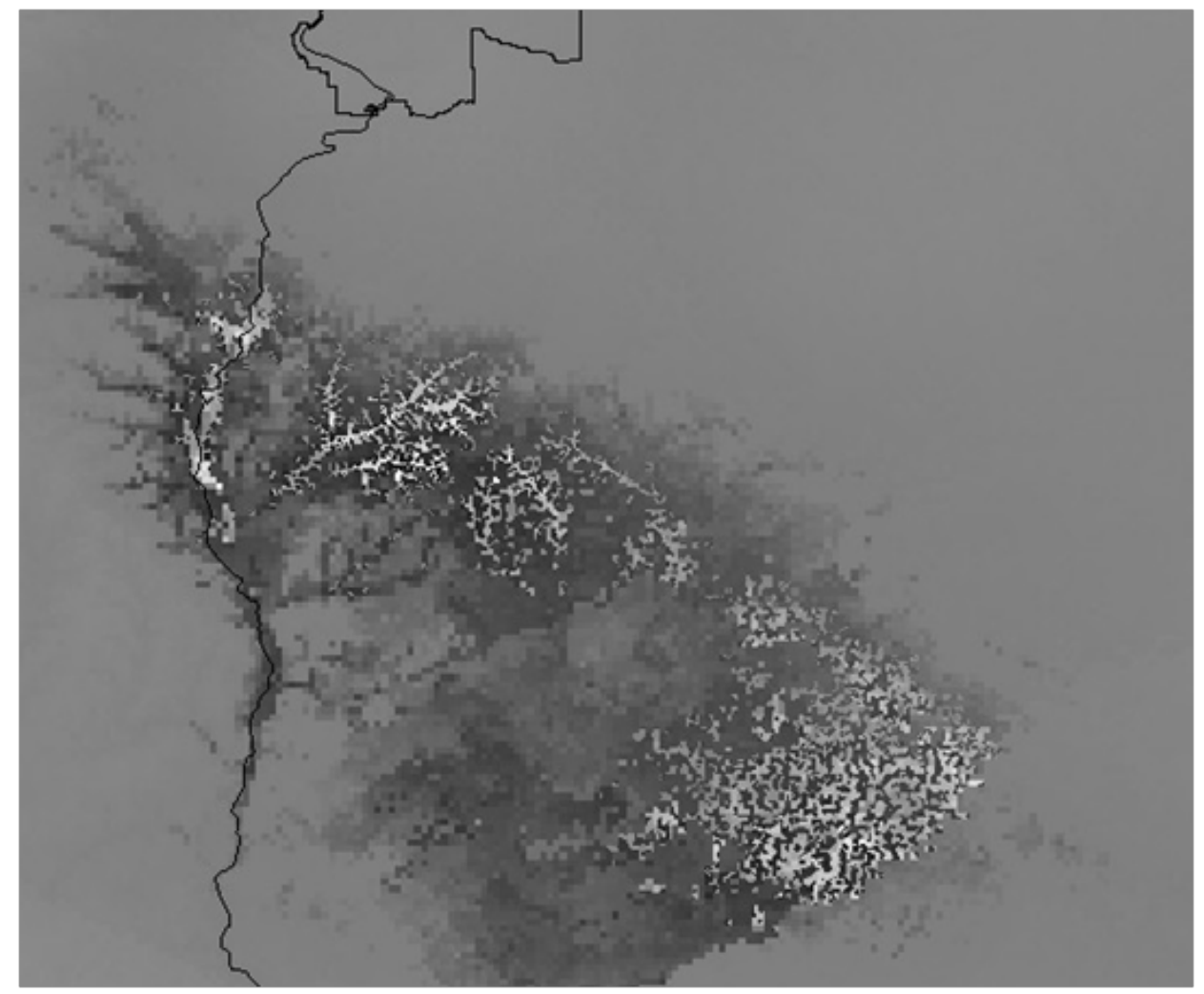


Figure 19. Lowland climate source for Fort Benning in 2085.

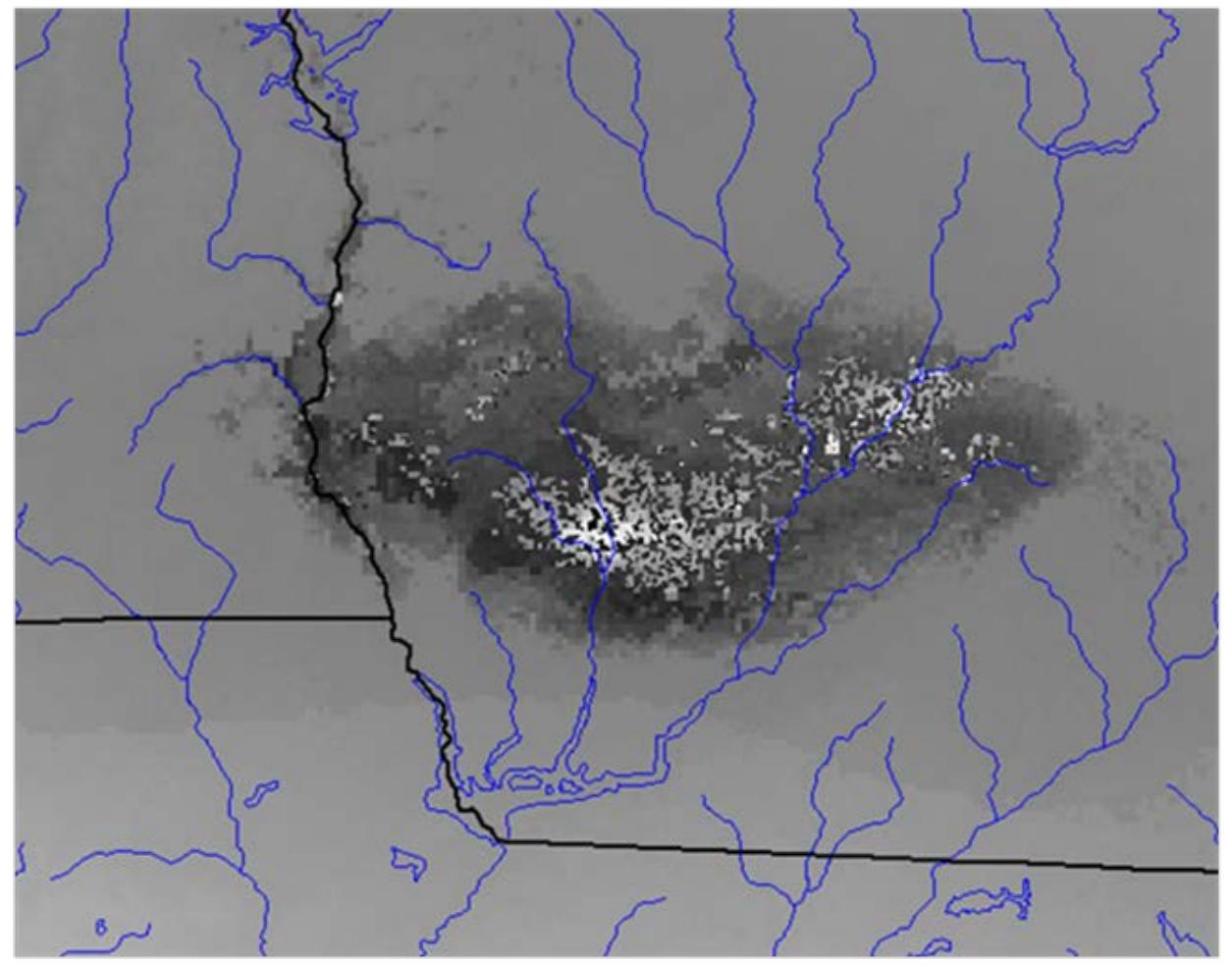

As mentioned earlier, there is an interesting additional locus of similar climatic habitat in central Alabama south of Selma. Focusing in on this area reveals a similar type fit between the chosen lowland areas (Figure 20) and river locations. This locus however is even brighter (meaning the fit is better) and more compact than the previous one near the Florida boundary. Furthermore, it is similarly poorly constrained by topography. This central Alabama location is currently highly characteristic of the climate in the Lower Upatoi River that Fort Benning can expect to experience in 2085.

\subsubsection{Migration of Fort Benning forest types - uplands}

This section investigates whether it is possible to distinguish a different type of vegetation migration over time. The type of vegetation chosen was upland pine types (shown as yellow in Figure 21) within a circle centered on the southeast corner of Fort Benning (also shown in Figure 21). Figure 22 shows the 1990 bioclimatic distribution of cells that coordinate closely with the upland pine tree species in the southeast corner of Fort Benning. 
Figure 20. Alternative lowland climate source from Alabama for Fort Benning in 2085.

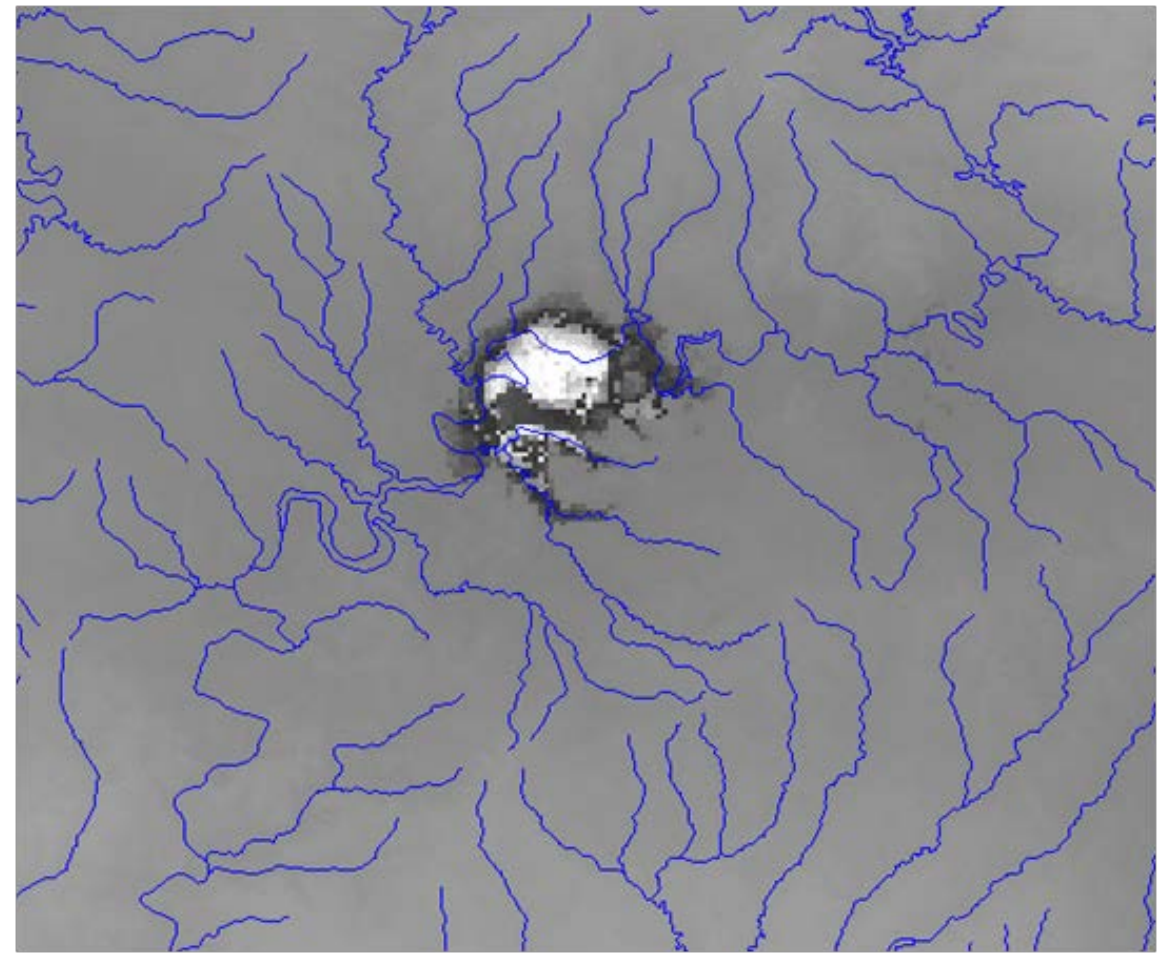

Figure 21. Generalize species from the Fort Benning Forest Inventory map. Upland types are in yellow. The target areas are the yellow within the circle centered on the southeast corner of the installation.

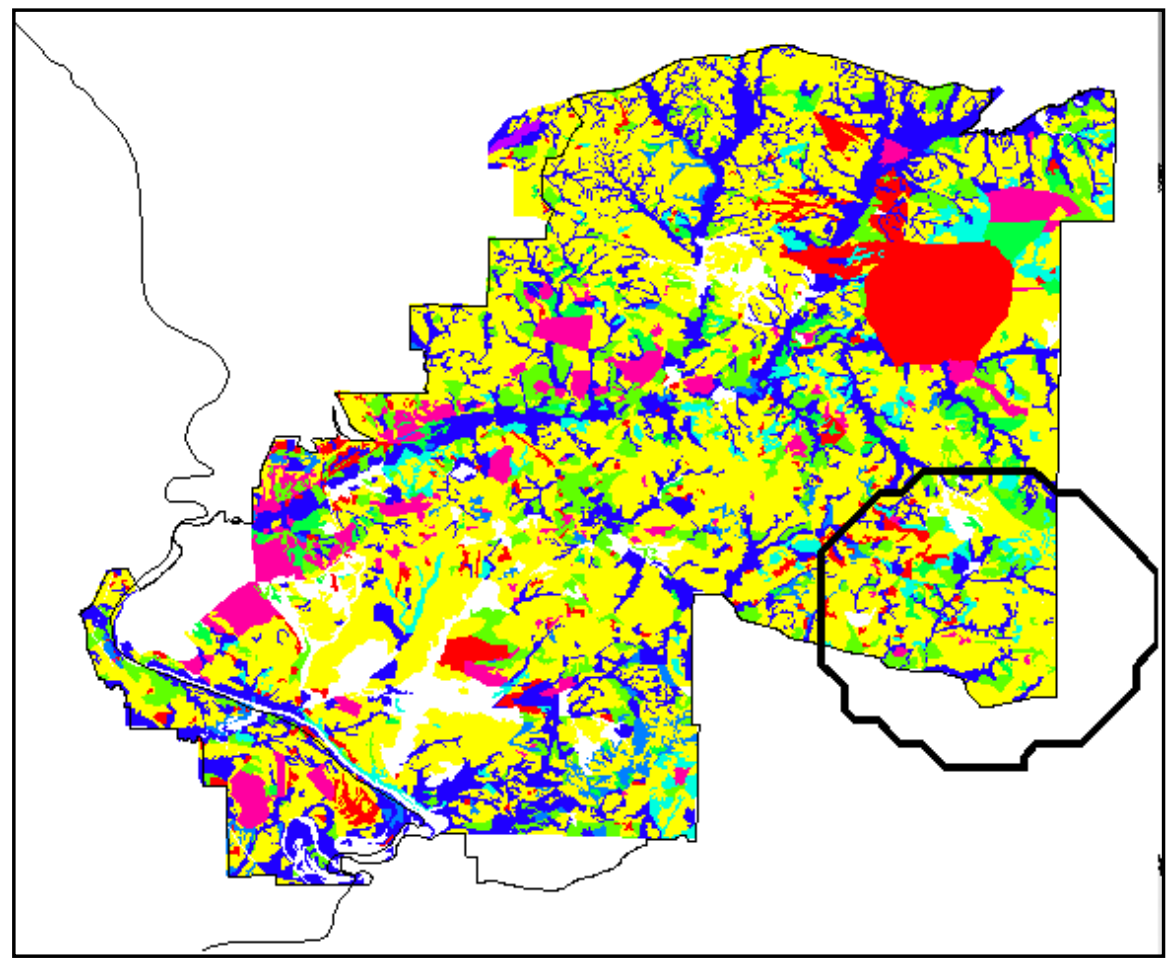


Figure 22. The 1990 bioclimatic distribution of cells that coordinate closely with the upland tree species similar to those in the southeast corner of Fig. 31.

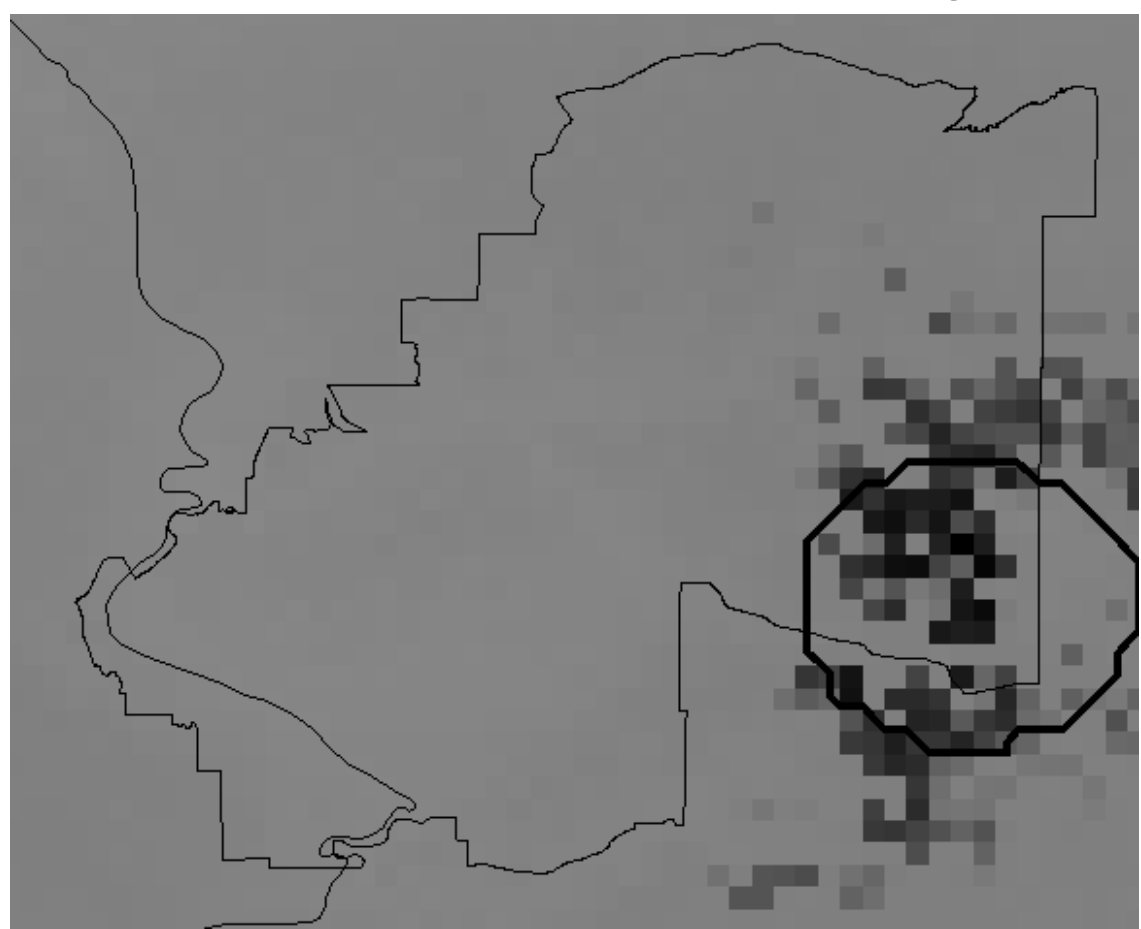

Figure 23 shows the resulting upland pine distribution for 2025. The darker grey areas show the full extent of the 2025 distribution (as previously shown in Figure 13 upper right) while the lighter grey areas show just the pixels chosen in this analysis. This time, the lighter areas tend to be congregated along the uplands between the ravines near the Chattahoochee River, particularly along the uplands between the ravines in the region south of Lumpkin about $50 \mathrm{~km}$ to the south of Fort Benning.

By 2055, the climate has encouraged the upland species to be derived from an area further south (Figure 24). Although the uplands near Hodchodkee and Pataula Creeks are still present in this analysis, it is their lower reaches (the more southerly) that are now favored. Furthermore, the southeast area, which only had a speckling of upland representatives in 2025, is now much more highly represented in 2055 . Note that, as one progresses to the south, the terrain changes from the rolling hills characteristic of Fort Benning to the flatter coastal plains where the drainage is more poorly defined (Figure 24). Because of this change in landform characteristics, the corresponding distinction between uplands and lowlands is less well defined and this is reflected in the resulting speckled patterns seen in this Coastal plains area. Figure 25 shows the same results draped over the topography. 
Figure 23. Fort Benning source for upland pine distribution for 2025 .

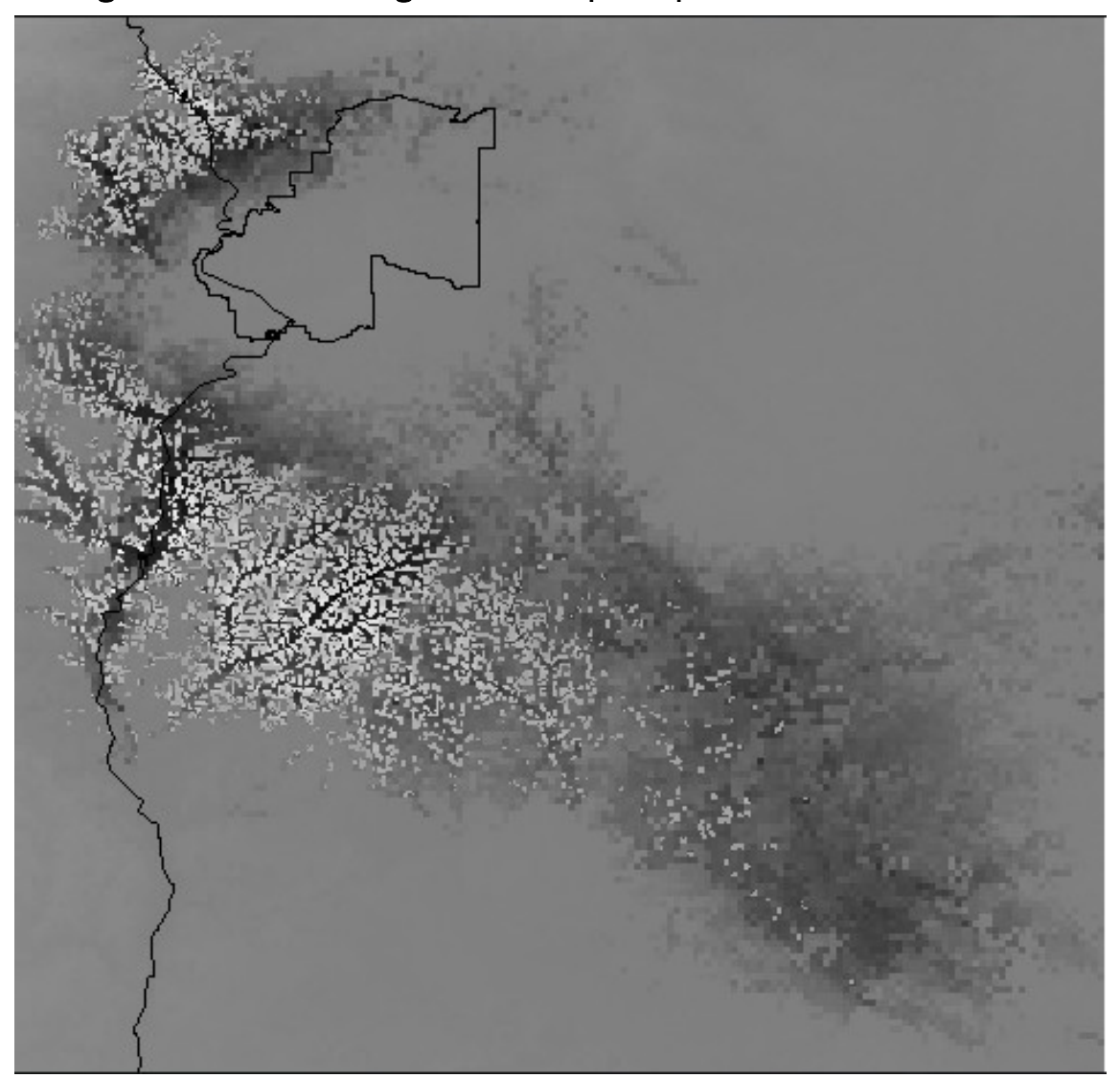

Figure 24. Fort Benning source for upland pine distribution for 2055.

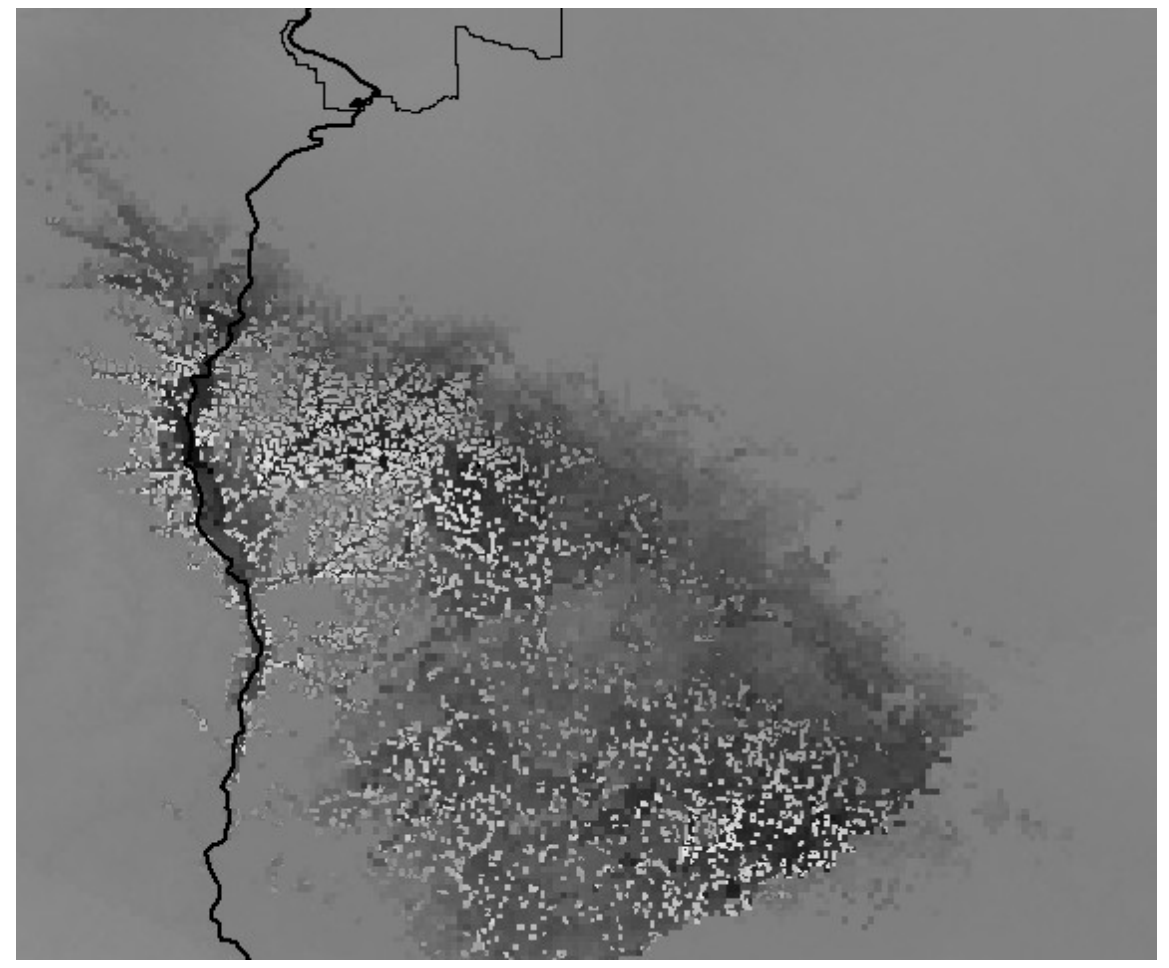


Figure 25. Upland pine distribution for 2055 (from Fig. 24) draped over the topography map.

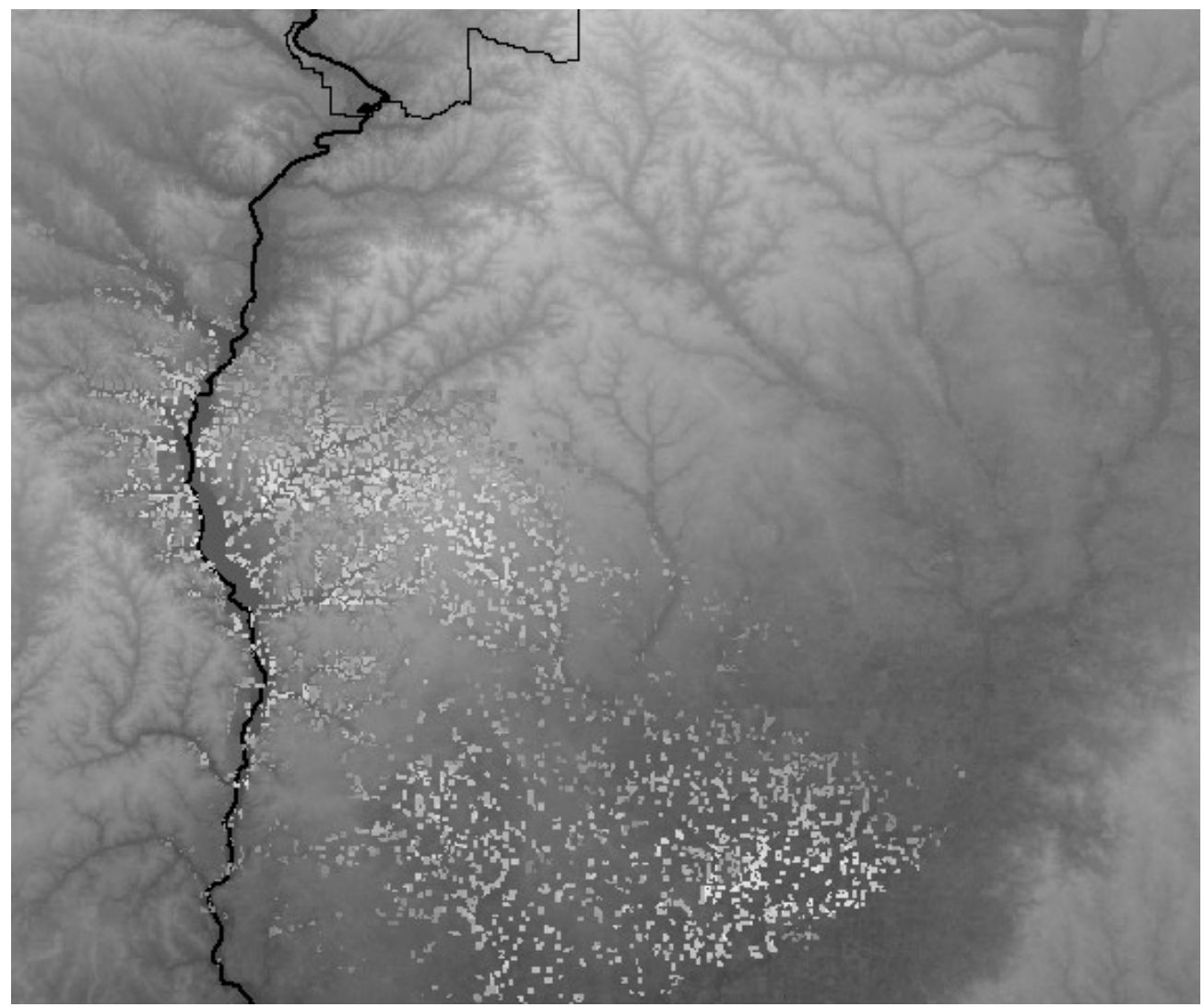

By 2085, the area from which upland vegetation is migrating is near the Florida border, but because of the indeterminate topography, the locations are scattered as shown in Figure 26.

\subsubsection{Analysis of the confusion between upland and lowland plant locations}

It is apparent in Figure 26 that the distinction between the upland and lowland species is less clear. Therefore, a research question of interest is:

How distinct is the delineation between upland and lowland sources at a specific time horizon?"

A sampling technique was developed to determine exactly how well this analysis separated the different areas identified in the previous two sections. Figure 27 shows, for the year 2025, the distribution of upland species (colored blue), lowland species (green) and the location where both upland and lowland species were identified in the same cell location (red). Red cells show the amount of "confusion" in this analysis. There are only a few red cells along the Chattahoochee River near Fort Benning. 
Figure 26. Fort Benning source for upland pine distribution for 2085.

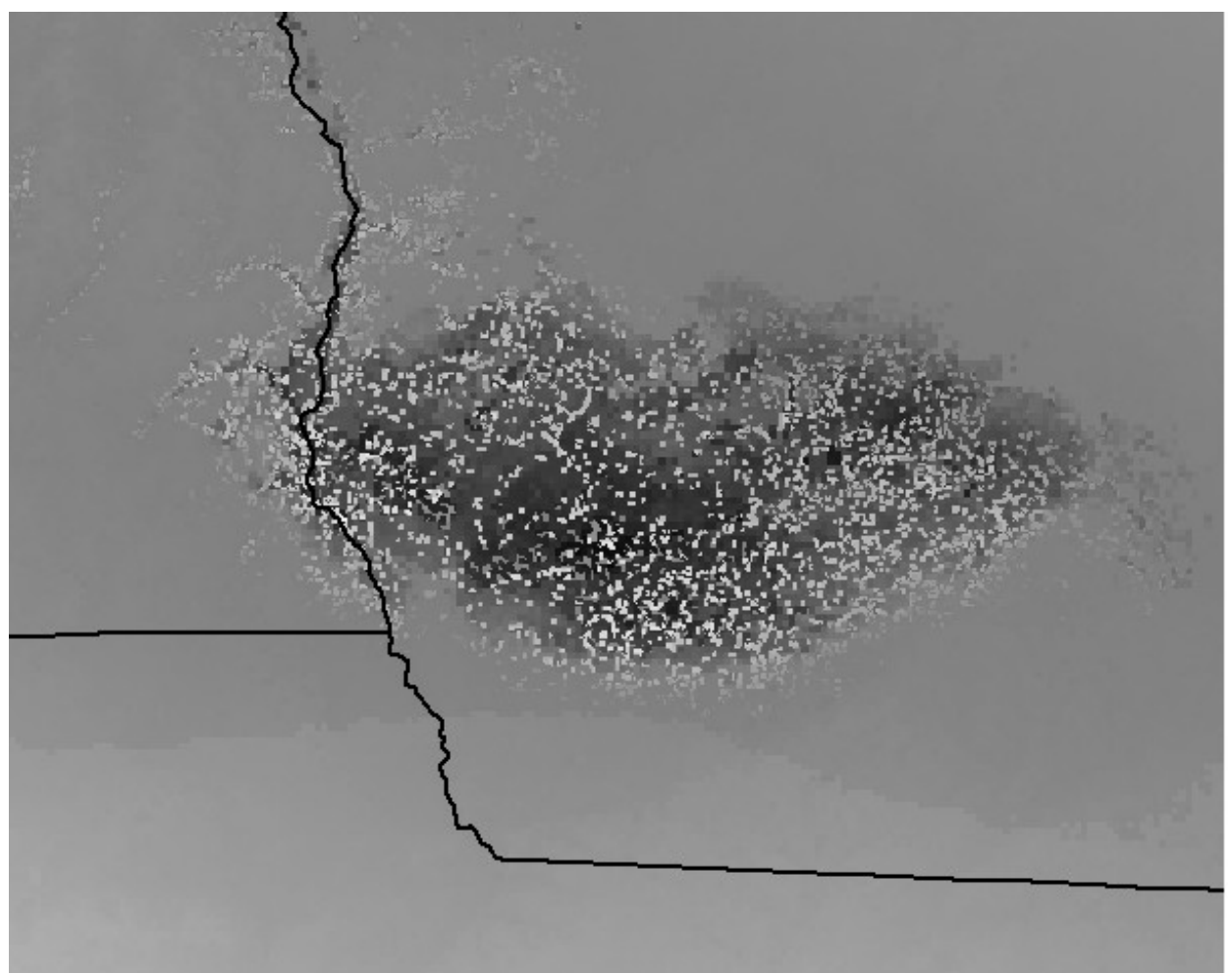

Figure 27. The distribution for the year 2025 of upland species (colored blue), lowland species (green) and where both upland and lowland species were identified in the same cell location (red).

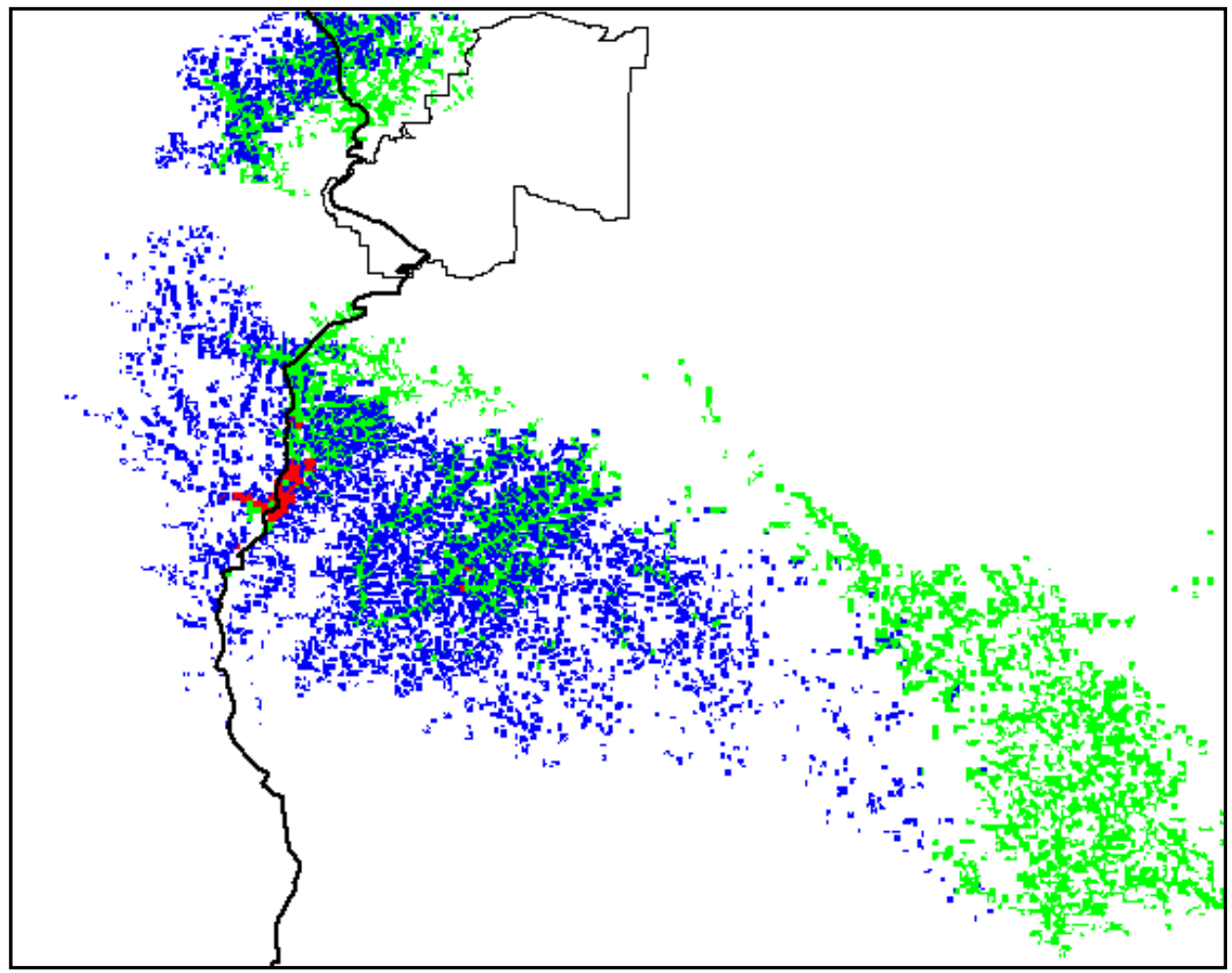


Table 7. Upland vs. lowland confusion table in each of the time horizons

\begin{tabular}{|l|l|l|l|l|l|}
\hline Time Horizon & Only Upland & Only Lowland & $\begin{array}{l}\text { Both Upland } \\
\text { and Lowland }\end{array}$ & $\begin{array}{l}\text { Total Number } \\
\text { of Cells } \\
\text { Identified }\end{array}$ & $\begin{array}{c}\text { Percent } \\
\text { Confused } \\
\text { Cells }\end{array}$ \\
\hline 2025 & 26596 & 31632 & 527 & 58755 & $0.90 \%$ \\
\hline 2055 & 30826 & 18773 & 0 & 49599 & $0.00 \%$ \\
\hline 2085 & 48726 & 14052 & 0 & 62778 & $0.00 \%$ \\
\hline
\end{tabular}

A similar analysis was carried out for the other two time horizons, 2055 and 2085. Table 7 lists the results of all three analyses; the data show that the distributions are almost mutually exclusive. (The worst case is less than $1 \%$ confusion for 2025.) Since the visual distribution of forest types for the 2085 distribution shown in Figure 24 was considered less distinct, the data in Table 7 indicate that the method works extremely well. This analysis is good evidence that sub-installation distributions of vegetative types can be reliably identified as climate changes occur over time.

\subsubsection{Invasive species based on the Primarily Analogous Multivariate approach}

Invasive Species (IS) can come from two sources:

- nearby similar areas

- distant locations with similar characteristics.

After exploring the potential sources of IS from nearby areas, one may also consider where analogous, distant locations exist. Assuming that species from distant locations that have a highly similar environment are most likely to successfully establish themselves around Fort Benning, the research question can now be rephrased as:

What are the bioclimatic regions elsewhere in the world that are most analogous to the region around Fort Benning?

Since climate change will alter the current most analogous area to a vicinity that might even have a different ecosystem, it is necessary to look both at analogous areas in the current time horizon as well as those in the future. The technique used here is comparable to the regional Primarily Analogous Multivariate approach, but applied globally. Figure 28 shows that, after the analysis, Fort Benning is fortunately similar to itself (very dark areas in the figure) and to the general region of the southeastern United States. There is no other extensive region in the world that is so akin to the southeastern United States. 
Figure 28. The resultant PAM bioclimatic regions elsewhere in the world that are most similar in 1990 to the region around Fort Benning (the darker, the more similar).

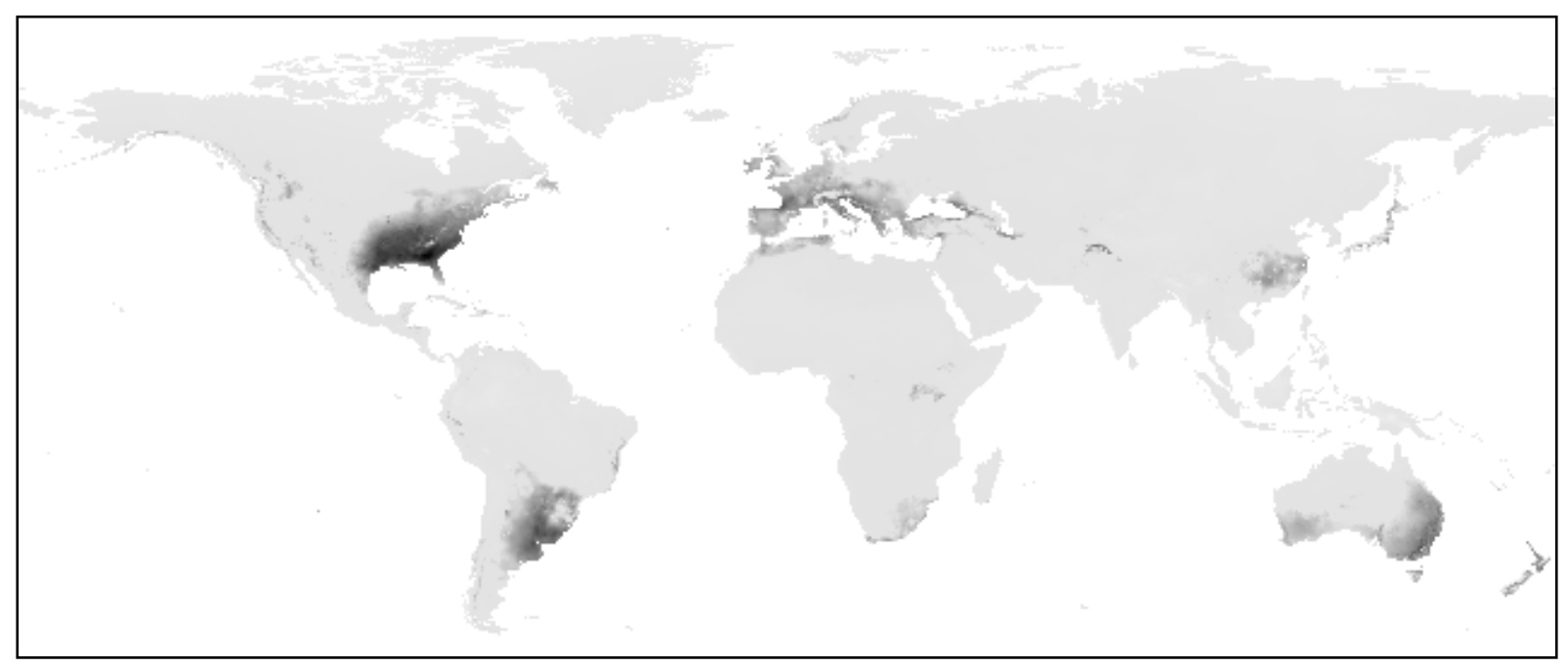

The hardiest invasives at Fort Benning are expected to be from the southeastern United States. However, some more distant regions are analogous. Specifically, in order of decreasing coverage, the similar areas are in:

- South America along the border of Uruguay and Argentina (the Parana River Valley)

- Along the eastern edge of Australia

- Southern Europe and northern Mediterranean

- East central China.

Although the Parana River area is more extensive, the volume of trade from Europe makes this a more likely source of foreign species. South American species may have a difficult task adapting to North America because the seasons are reversed. This is not true of European or Asian species. These are the areas from which invasives are most likely to come that end up in the southeast United States.

The companion analysis for 2085 is instructive (Figure 29). It shows shrinkage of similar areas from Europe. On the other hand, the region around the Parana has increased as has the region in China. Small new areas can now be seen intensifying in Northern Pakistan. Australia has become less intensely similar, but that which exists has spread over much more of the continent. Finally the Sahel region of Africa has now emerged prominently whereas it was barely represented in 1990 . 
Figure 29. The PAM analysis for $\mathbf{2 0 8 5}$ for the bioclimatic regions that are most similar to the region around Fort Benning.

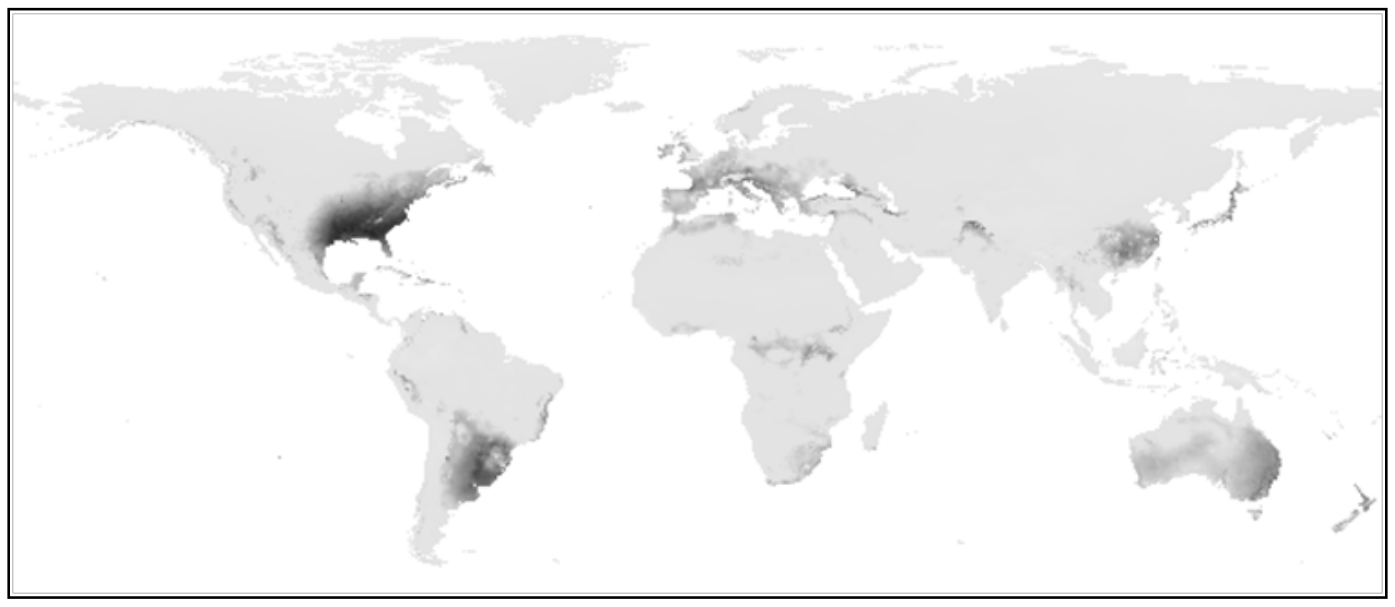

This suggests that, with increased trade, invasives from the Parana basin will become more significant to Fort Benning. China, Australia, the Sahel and Northern Pakistan will provide more adopted IS to the installation than they do now. However, invasives from the southeast region of the United States are still likely to have an easier time finding a foothold at Fort Benning.

The US Army Floristic Inventories database (HQUSACE 2007) lists 101 exotic vascular plant species at Fort Benning. Of those, the species that are most often the focus of attention include: Perennial Kudzu (Pueraria lobata), Chinese Bush Clover (Lespedeza cuneata), Oriental Bittersweet (Celastrus orbiculatus), Butternut Canker (Sirococcus clavigignentijuglandacearum) and Cogon grass (Imperata cylindrica). ${ }^{*}$ Kudzu is native to the Indian subcontinent; Chinese Bush Clover is from Asia and eastern Australia; Oriental Bittersweet is native to East Asia; Butternut Canker is possibly from Asia; and Cogon grass is native to east and southeast Asia, India, Micronesia, Australia, and eastern and southern Africa. One of the listed exotics is South American mock vervain (Glandularia pulchella), which is native to Brazil, Argentina, and Uruguay.

These similar areas are all represented in Figures 28 and 29. The prevalence of Asian invasives suggests strong historical trade connections. The lack of problem species from Europe is interesting to note. It has been

\footnotetext{
* http://workshops.serdp-

estcp.org/serps/docs/Southeastern_Regional_Conservation_Research_Projects.pdf
} 
suggested that European invaders have been in the United States long enough that they are now considered naturalized. No references were found to support this suggestion.

Table 8 lists the proposed exotic pest plant species for the State of Georgia (Murphy 2005). All of them come from Asia, usually China.

The analysis in this section suggests that more invasives may be expected to arrive in the southeastern United States from China due to climate change.

Table 8. Proposed exotic pest plant species for Georgia.

\begin{tabular}{|c|c|c|}
\hline Common Name & Scientific Name & Native Land* \\
\hline Kudzu & Pueraria montana (Lour.) Merr. & Indian Subcontinent \\
\hline Chinese privet & Ligustrum sinense Lour. & China, Taiwan and Vietnam \\
\hline apanese honeysuckle & Lonicera japonica Thunb. & China, Japan and Korea \\
\hline Hydrilla & Hydrilla verticillata (L. f.) Royle & $\begin{array}{l}\text { Asia, Europe, Africa and } \\
\text { Australia }\end{array}$ \\
\hline Chinese tallow tree & Triadica sebifera (L.) Small & $\begin{array}{l}\text { Eastern China, Taiwan, and } \\
\text { Japan }\end{array}$ \\
\hline Nepalese browntop & $\begin{array}{l}\text { Microstegium vimineum (Trin.) A. } \\
\text { Camus }\end{array}$ & Iran in the west, east to China \\
\hline Bamboo & $\begin{array}{l}\text { Phyllostachys aurea Carr. ex A.\& } \\
\text { C. Rivière }\end{array}$ & China \\
\hline Autumn olive (silverberry) & Elaeagnus umbellata Thunb. & Eastern Asia to Japan \\
\hline Chinese wisteria & Wisteria sinensis (Sims) DC. & China \\
\hline Mimosa & Albizia julibrissin Durazz. & Southwestern to eastern Asia \\
\hline
\end{tabular}




\section{Comparison of the Different Multivariate Approaches}

\subsection{The evaluation of the different techniques}

This research investigated the application success and versatility of six different multivariate approaches. Two approaches, (CCA) and an SMAP estimation, provided no usable signature files after expending a great deal of effort. Table 9 lists a summary of the evaluation of the six MVAs applied in this work.

Table 9. Evaluation of six MVAs.

\begin{tabular}{|c|c|c|}
\hline Approach & Pros & Cons \\
\hline $\begin{array}{l}\text { Unsupervised } \\
\text { Classification }\end{array}$ & $\begin{array}{l}\text { - Well accepted and understood procedure } \\
\text { - Requires minimal data preparation } \\
\text { - Requires minimal additional user input } \\
\text { - Requires few assumptions on the part of } \\
\text { the user } \\
\text { - Results are roughly consistent } \\
\text { independent of the number of layers } \\
\text { input }\end{array}$ & $\begin{array}{l}\text { - Results are not tied to known attributes } \\
\text { on the land } \\
\text { - Lack of output control } \\
\text { - Did not result in patches that can be } \\
\text { followed through time } \\
\text { - User cannot control well the character of } \\
\text { the output - this is mostly determined by } \\
\text { the algorithm }\end{array}$ \\
\hline $\begin{array}{l}\text { Supervised } \\
\text { Classification }\end{array}$ & $\begin{array}{l}\text { - Well accepted and understood procedure } \\
\text { - Requires training map - you know the } \\
\text { meaning of the resultant areas } \\
\text { - Resulted in patches that can be followed } \\
\text { through time }\end{array}$ & $\begin{array}{l}\text { - User cannot control well the character of } \\
\text { the output - this is mostly determined by } \\
\text { the algorithm } \\
\text { - Requires training map }\end{array}$ \\
\hline $\begin{array}{l}\text { Principal } \\
\text { Components }\end{array}$ & $\begin{array}{l}\text { - Sophisticated analysis approach } \\
\text { - Reforms the data to make them more } \\
\text { acceptable to classifying programs } \\
\text { - Level of variance in data numerically } \\
\text { assured }\end{array}$ & $\begin{array}{l}\text { - Lack of output control } \\
\text { - Did not result in patches that can be } \\
\text { followed through time } \\
\text { - Data are tertiary in generation - there is } \\
\text { a chance the original information value } \\
\text { has been lost }\end{array}$ \\
\hline $\begin{array}{l}\text { Primarily } \\
\text { Analogous } \\
\text { Multivariate } \\
\text { Approach }\end{array}$ & $\begin{array}{l}\text { - Easy to conceptually describe } \\
\text { - Easy to carry out } \\
\text { - It puts no restrictions on the input data } \\
\text { - Guaranteed to result in patches that can } \\
\text { be followed through time } \\
\text { - Versatile - allows sub-installation and } \\
\text { global level analyses }\end{array}$ & - Not sophisticated in concept \\
\hline $\begin{array}{l}\text { Canonical } \\
\text { Components } \\
\text { Analysis }\end{array}$ & $\mathrm{N} / \mathrm{A}$ & Produced no results \\
\hline SMAP Estimation & $\mathrm{N} / \mathrm{A}$ & Produced no results \\
\hline
\end{tabular}




\subsection{The effect of the Benning Hole on the results}

Chapter 3 discussed an anomaly in the data, called the "Benning Hole," in which "patches 50 kilometers to the east of the installation are expected to be more similar to the installation than areas on it or more immediately adjacent." Evidence suggests that this potential anomaly influenced the results of these analyses.

Several of the outputs show a clear east-west bias (as shown in Figure 8 in particular, but also in Figures 4, 9, 10, 24, and 25). In other words, several of the analyses support the hypothesis that an east-west component seems to exist. More specifically, the analysis indicates that "the current

Bioclimatic at Benning will go" on a West to East track (Figure 12) instead of a south to north track. On the other hand, the elevation rises quickly to the north of the installation that a purely northerly migration would not be expected on that basis alone. There is evidence (but no clear proof) for the influence of the hole in the results.

On the other hand, most of analyses show the new Fort Benning climate migrating from south to north (particularly Figure 13), roughly perpendicular to the trend of the values associated with the hole. The final conclusion on the issue is that, if the hole influences the result, it is not great enough to overpower the overall migration of the bioclimate in a direction perpendicular to that which the hole should produce. 


\section{Conclusions and Recommendations}

\subsection{Conclusions}

Changes in climatic parameters are important in that they affect the military's ability to perform its national defense mission to manage military lands within the continental United States (CONUS). The military must have the ability to predict climatic changes on specific installations. To support this need, the research has outlined and evaluated the application of MVA techniques to predict climatic changes on a specific Army installation, Fort Benning GA.

To accomplish the evaluation, a database was created of 19 bioclimatic parameters that represented a consensus of six GCMs and three future scenarios for each of the time periods centered around the dates 1990, 2025, 2055, and 2085. Once in place, this data helped to form a solid base that made it possible to reliably track the predicted changes. Several MVA techniques were applied to the data and the outcomes were compared.

The results of almost all the investigations indicated that predicted climate change was found to be great enough so that almost no place over the entire installation would be the same in 2025 as it had been in 1990.

Of the six MVA techniques evaluated, four provided usable results:

- Unsupervised Classification

- Supervised Classification

- Principal Components

- Primarily Analogous Multivariate.

The Supervised Classification and the Primarily Analogous approaches produced usable predictions for all four time periods. The Unsupervised Classification and Principal Components techniques produced usable predictions for only 2025.

The evaluation found that the Primarily Analogous Multivariate approach developed during this research clearly distinguished itself from the other five approaches in that it:

- was easy to conceptualize

- was easy to carry out

- required no restrictions on the input data 
- guaranteed that results could be generated at each time horizon

- was highly versatile in that it successfully supported application from the sub-installation to the global scales.

Of the six approaches evaluated, two (the Supervised Classification and PAM) could fulfill the primary objective of this research, to determine "the climatic factors in the future at the installation."

Of the six approaches evaluated, one (PAM) could fulfill the secondary objective of this research, to determine whether "an analysis at the subinstallation level can be successfully accomplished with the currently available climatic data."

\subsection{Recommendations}

As a result of this investigation, it is recommended that research continue to develop the capability to anticipate and predict how the bioclimate will change over time at a particular installation. Furthermore, it is recommended to promote the application of the Primarily Analogous Multivariate approach to analyze climate change at the sub-installation level. This simplest of the six evaluated approaches always produced usable, reliable, detailed outputs, and exhibited the greatest versatility in being applied to different issues at scales from the sub-installation to the global level. 


\section{Acronyms and Abbreviations}

$\begin{array}{ll}\text { Term } & \text { Definition } \\ \text { CCA } & \text { Canonical Components Analysis } \\ \text { CEQ } & \text { Council on Environmental Quality } \\ \text { CERL } & \text { Construction Engineering Research Laboratory } \\ \text { CIAT } & \text { International Centre for Tropical Agriculture } \\ \text { CONUS } & \text { Continental United States } \\ \text { DoD } & \text { US Department of Defense } \\ \text { ERDC } & \text { US Army Engineer Research and Development Center } \\ \text { ERDC-CERL } & \text { Engineer Research and Development Center, Construction Engineering } \\ & \text { Research Laboratory } \\ \text { GCM } & \text { Global Climate Model } \\ \text { GFDL } & \text { Geophysical Fluid Dynamics Laboratory } \\ \text { GISS } & \text { Goddard Institute for Space Studies } \\ \text { IEEE } & \text { Institute of Electrical and Electronics Engineers } \\ \text { INRMP } & \text { Integrated Natural Resources Management Plans } \\ \text { IPCC } & \text { Intergovernmental Panel on Climate Change } \\ \text { IS } & \text { Invasive Species } \\ \text { MVA } & \text { Multivariate Analysis } \\ \text { NASA } & \text { National Aeronautics and Space Administration } \\ \text { NCAR } & \text { National Centre for Atmospheric Research } \\ \text { NEPA } & \text { National Environmental Policy Act } \\ \text { NOAA } & \text { National Oceanic and Atmospheric Administration } \\ \text { NSN } & \text { National Supply Number } \\ \text { OMB } & \text { Office of Management and Budget } \\ \text { PAM } & \text { Primarily Analogous Model } \\ \text { PCA } & \text { Principal Components Analysis } \\ \text { QDR } & \text { Quadrennial Defense Review } \\ \text { SMAP } & \text { Sequential Maximum A Posteriori } \\ \text { SR } & \text { Special Report } \\ \text { SRES } & \text { The Special Report on Emissions Scenarios } \\ \text { TAR } & \text { Third Assessment Report } \\ \text { TR } & \text { Technical Report } \\ \text { URL } & \text { Universal Resource Locator } \\ \text { US } & \text { United States } \\ \text { USA } & \text { United States of America } \\ \text { WWW } & \text { World Web } \\ & \end{array}$




\section{References}

Archive Collaborators. 2013. Downscaled CMIP3 and CMIP5 Climate and Hydrology Projections. Web site. Archive Collaborators (Bureau of Reclamation, Climate Analytics Group, Climate Central, Lawrence Livermore National Laboratory, Santa Clara University, Scripps Institution of Oceanography, US Army Corps of Engineers, and US Geological Survey). Accessed 6 De ember 2013, http://gdo-dcp.ucllnl.org/downscaled_cmip3_projections/dcplnterface.html

Ball, Geoffrey H., and David J . Hall. 1965. Isodata: A method of data analysis and pattern classification. Menelo Park,CA: Office of Naval Research, Information Sciences Branch, Stanford Research Institute.

Duda, R. O., P. E. Hart, and D. G. Stork . 2001. Pattern classification. New York: J ohn Wiley \& Sons.

ERDAS, Inc. 2010. ERDAS Field Guide. Atlanta GA: ERDAS, Inc.

GRASS Development Team. 2012. i.cluster. The GRASS 4 Image processin Manual. Web page. Accessed 6 December 2013, http://grass.fbk.eu/grass64/manuals/html64 user/i.cluster.html

Haralick, R. M. 1979. Statistical and structural approaches to texture. Proceedings of the IEEE 67(5):786-804.

Hargrove, William W., and Forrest Hoffman. 2004. Potential of multivariate quantitative methods for delineation and visualization of ecoregions, Environmental Management 34(1):S39-S60. DOI 10.1007/s00267-003-1084-0.

Headquarters, US Army Corps of Engineers (HQUSACE). 2007. US Army Installation Floristic Inventory Database. Public Works Technical Bulletin (PWTB) 200-1-52. Washington, DC: HQUSACE, http://www.wbdg.org/ccb/ARMYCOE/PWTB/pwtb_200_1_52.pdf

Hijmans, Robert J ., Susan E. Cameron, J uan L. Parra, Peter G. J ones, and Andy J arvisc. 2005. Very high resolution interpolated climate surfaces for global land areas. International J ournal of Climatology 25:1965- 1978.

Intergovernmental Panel on Climate Change (IPCC). 2013. Working Group II: Impacts, Adaptation, and Vulnerability. Fifth Assessment Report (AR5).

2007a. Summary for policymakers. In S. Solomon, D. Qin, M. Manning, Z. Chen, M. Marquis, K. B. Averyt, M.Tignor and H. L. Miller (eds.). Climate change 2007: The physical science basis. Contribution of working group i to the fourth assessment report of the Intergovernmental Panel on Climate Change. Cambridge, UK and New York, NY: Cambridge University Press. 
2007b. The physical science basis, contribution of Working Group I to the Fourth Assessment Report of the Intergovernmental Panel on Climate Change. In S. Solomon, D. Qin, M. Manning, Z. Chen, M. Marquis, K. B. Averyt, M. Tignor and H. L. Miller (eds.). Climate change 2007: The physical science basis. Contribution of Working Group I to the Fourth Assessment Report of the Intergovernmental Panel on Climate Change. Cambridge, UK and New York, NY: Cambridge University Press.

Jensen, J. R. 1996. Introductory digital image processing: A remote sensing perspective. NewJ ersey: Prentice-Hall Inc., NJ .

Lozar, Robert C., Matthew Hiett, and J ames Westervelt. 2011. Anticipating climate change impacts on Army installations. Special Report. ERDC SR-11-1. Champaign, IL: Engineer Research and Development Center (ERDC), http://acwc.sdp.sirsi.net/client/search/asset:asset?t:ac=\$N/100636

2012. Anticipating Installation Natural Resource Climate Change Concerns: Analysis Demonstration. Draft Technical Report. Champaign, IL: ERDC-CERL.

2013. Anticipating installation natural resource climate change concerns: The data. Technical Report. ERDC/ CERL TR-13-23. Champaign, IL: ERDC-CERL, http://acwc.sdp.sirsi.net/client/search/asset/1032342

Murphy, Tim R. 2005. Proposed exotic pest plant species for Georgia. Web page. Accessed 04 December 2013, http://www.gaeppc.org/exotalk1.html

Ramirez, J ulian, and Andy J arvis. 2010. Disaggregation of global circulation model outputs decision and policy analysis. Working Paper No. 2. Cali, Colombia: International Centre for Tropical Agriculture (CIAT).

Sprinthall, R. C. 2003. Basic Statistical Analysis. $7^{\text {th }}$ ed. Boston : Allyn and Bacon.

Sutley, Nancy H. (Chair, Council on Environmental Quality [CEQ]). 2010. Memorandum. Subject: Draft NEPA Guidance on Consideration of the Effects of Climate Change and Greenhouse Gas Emissions. Washington, DC: The White House, http://www.whitehouse.gov/sites/default/files/microsites/ceq/20100218-nepa-considerationeffects-ghg-draft-guidance.pdf

US Department of Defense (DOD). 2010. Quadrennial defense review report. Washington DC: DoD, http://www.defense.gov/qdr/images/QDR_as_of_12Feb10_1000.pdf

2012. Considerations and recommendations when developing Department of Defense Integrated Natural Resource Management Plans. Project \# 07-356. Washington, DC: DoD, http://www.denix.osd.mil/nr/upload/07-356-FS_-Considerations-and-Recommendations-forINRMP-development.pdf

US Fish and Wildlife Service (USFWS). Undated. Eufaula National Wildlife Refuge. Web page. Accessed 5 December 2013, http://www.fws.gov/refuges/profiles/index.cfm?id=43560 
Westervelt, James, and William Hargrove. 2011. Forecasting climate-induced ecosystem changes on Army installations. ERDC/ CERL TR-11-36, http://acwc.sdp.sirsi.net/client/search/asset:asset?t:ac=\$N/1006341

Wikipedia. 2013. Standard Score. Web page. Accessed 6 December 2013,: http://en.wikipedia.org/wiki/Standard_score (derived from: Richard J . Larsen and Morris L. Marx. 2000. An Introduction to Mathematical Statistics and Its Applications. 3d ed. Cambridge, UK: Pearson Education :Ltd., p 282).

WorldClim. 2013. WorldClim - Global Climate Data: Free Climate Data for Ecological Modeling and GIS. Website. Accessed 6 December 2013,

WorldClim site at http://www.worldclim.org/current 


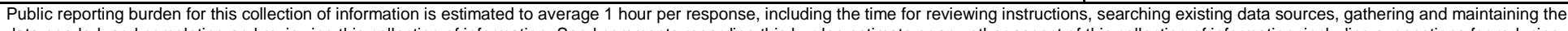

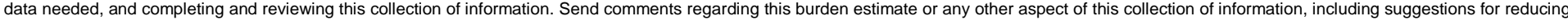

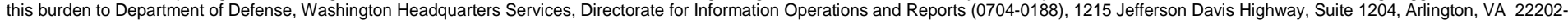

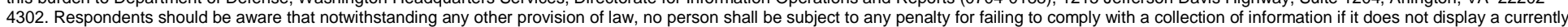
valid OMB control number. PLEASE DO NOT RETURN YOUR FORM TO THE ABOVE ADDRESS.

\begin{tabular}{l|l} 
valid OMB control number. PLEASE DO NOT RETURN YOUR FORM TO THE ABOVE ADDRESS. \\
\hline 1. REPORT DATE (DD-MM-YYYY) 2. REPOR
\end{tabular}

\begin{tabular}{|c|c|} 
06-02-2015 & Final \\
\hline
\end{tabular}

\section{TITLE AND SUBTITLE}

Multivariate Bioclimatic Ecosystem Change Approaches

3. DATES COVERED (From - To)

5a. CONTRACT NUMBER

5b. GRANT NUMBER

\section{5c. PROGRAM ELEMENT}

\section{AUTHOR(S)}

Robert C. Lozar and J ames D. Westervelt

\section{5d. PROJECT NUMBER}

5e. TASK NUMBER

5f. WORK UNIT NUMBER

7. PERFORMING ORGANIZATION NAME(S) AND ADDRESS(ES)

U.S. Army Engineer Research and Development Center (ERDC)

Construction Engineering Research Laboratory (CERL)

PO Box 9005,

Champaign, IL 61826-9005

8. PERFORMING ORGANIZATION REPORT NUMBER

ERDC/ CERL TR-15-2

\section{SPONSORING / MONITORING AGENCY NAME(S) AND ADDRESS(ES)}

U.S. Army Engineer Research and Development Center (ERDC)

Construction Engineering Research Laboratory (CERL)

PO Box 9005

Champaign, IL 61826-9005

\section{DISTRIBUTION I AVAILABILITY STATEMENT}

Approved for public release; distribution is unlimited.

\section{SUPPLEMENTARY NOTES}

\section{ABSTRACT}

Changes in climatic parameters are important in that they affect the military’s ability to perform its national defense mission and to manage military lands. The military must have the ability to predict climatic changes on specific installations. To support this need, the research tested and evaluated the application of six multivariate approach techniques to predict climatic changes on a specific Army installation, Fort Benning, GA. The six approaches were tested for their ability to identify where anticipated future conditions might be found today using a set of 19 bioclimatic parameters derived from climate change data. The evaluation found that the Primarily Analogous Multivariate approach developed during this research clearly distinguished itself from the other five approaches in that it successfully determined future climatic factors at the installation, as well as at the sub-installation level using the currently available climatic data.

\section{SUBJECT TERMS}

climate change, Ft. Benning, GA, natural resource management, modeling, land use planning

\begin{tabular}{l} 
16. SECURITY CLASSIFICATION OF: \\
\hline \begin{tabular}{c|c|c|}
\hline $\begin{array}{c}\text { a. REPORT } \\
\text { Unclassified }\end{array}$ & $\begin{array}{c}\text { b. ABSTRACT } \\
\text { Unclassified }\end{array}$ & $\begin{array}{c}\text { c. THIS PAGE } \\
\text { Unclassified }\end{array}$ \\
\hline
\end{tabular}
\end{tabular}

NSN 7540-01-280-5500

\begin{tabular}{|c|c|c|}
\hline $\begin{array}{c}\text { 17. LIMITATION } \\
\text { OF ABSTRACT }\end{array}$ & $\begin{array}{r}\text { 18. NUMBER } \\
\text { OF PAGES }\end{array}$ & $\begin{array}{c}\text { 19a. NAME OF RESPONSIBLE PERSON } \\
\text { SAR }\end{array}$ \\
\cline { 3 - 3 } & 67 & $\begin{array}{c}\text { 19b. TELEPHONE NUMBER } \\
\text { (include area code) }\end{array}$ \\
\hline
\end{tabular}

